\title{
1 Rapid shift in substrate utilization driven by hypothalamic Agrp neurons
}

\section{Authors:}

4 João Paulo Cavalcanti-de-Albuquerque ${ }^{1}$, Marcelo R. Zimmer ${ }^{1}$, Jeremy Bober ${ }^{1}$, and Marcelo O. 5 Dietrich $^{1,2}$

8 Affiliations:

$9{ }^{1}$ Section of Comparative Medicine, Yale University School of Medicine, New Haven, CT -

1006520 - USA.

$11{ }^{2}$ Department of Neuroscience, Yale University School of Medicine, New Haven, CT - 06520 -

12 USA.

13

\section{Contact:}

15 marcelo.dietrich@yale.edu 


\section{Abstract}

2 Agrp neurons drive feeding. To what extend these neurons participate in the regulation of other

3 homeostatic processes is not well understood. We investigated the role of Agrp neurons in

4 substrate utilization in mice. Activation of Agrp neurons was sufficient to rapidly increase RER

5 and carbohydrate utilization, while decreasing fat utilization. These metabolic changes were

6 linearly correlated with carbohydrates ingested, but not protein or fat ingestion. However, even

7 in the absence of ingestive behaviors, activation of Agrp neurons led to changes in substrate

8 utilization in well-fed mice. These effects were coupled to metabolic shifts towards lipogenesis.

9 Inhibition of fatty acid synthetase (FAS) blunted the effects of Agrp neurons on substrate

10 utilization. Finally, Agrp neurons controlled peripheral metabolism, but not food intake, via 33 -

11 adrenergic receptor signaling in fat tissues. These results reveal a novel component of Agrp

12 neuron-mediate metabolism regulation that involves sympathetic activity on fat compartments to

13 shift metabolism towards lipogenesis. 


\section{Introduction}

Obesity is a major health problem that results from altered regulation of energy

3 metabolism. The central nervous system tightly controls energy metabolism by regulating

4 hormonal and autonomic action on peripheral tissue. The hypothalamus is a conserved region in

5 the brain involved in homeostatic control, including energy balance. The arcuate nucleus of the

6 hypothalamus contains a population of neurons that selectively expresses agouti-related protein

7 (AgRP; hereafter, Agrp neurons) (Broberger et al., 1998; Hahn et al., 1998; Ollmann et al., 1997;

8 Rossi et al., 1998). Agrp neurons are located in proximity to the third ventricle and have direct

9 access to circulation (Olofsson et al., 2013), as this brain region lacks a complete blood-brain

10 barrier (Broadwell et al., 1983; Broadwell and Brightman, 1976). Consistently, Agrp neurons are

11 known to respond to a variety of circulating factors (Könner et al., 2007; Pinto et al., 2004;

12 Steculorum et al., 2015; van den Top et al., 2004). However, recent evidence demonstrates that

13 Agrp neurons also integrate food-related information via sensory pathways (Betley et al., 2015;

14 Chen et al., 2015; Mandelblat-Cerf et al., 2015). Thus, Agrp neurons are unique as they gather

15 relevant information from several sources to regulate physiology and behavior.

16 Agrp neurons were first described to be active during food deprivation, a phenomenon

17 conserved across rodent and non-human primate species (Grove et al., 2003; Hahn et al., 1998;

18 Mandelblat-Cerf et al., 2015; Takahashi and Cone, 2005). Because Agrp neurons co-express

19 NPY (Broberger et al., 1998; Hahn et al., 1998), and because NPY acts as a potent orexigenic

20 peptide when injected into the brain (Clark et al., 1984), it was natural to conclude that during

21 food deprivation Agrp neurons are active to drive food intake. Subsequent work demonstrated

22 that activation of Agrp neurons is sufficient to drive food intake in sated mice (Aponte et al., 
1 2011; Dietrich et al., 2015; Krashes et al., 2011). Conversely, elimination of Agrp neurons in the

2 adult brain led to aphagia (Gropp et al., 2005; Luquet et al., 2005).

3 Recent work demonstrated a specific role for Agrp neurons in metabolic processes,

4 including the control of white adipose tissue (WAT) browning and thermogenesis (Ruan et al.,

5 2014), as well as brown adipose tissue (BAT) glucose metabolism (Steculorum et al., 2016).

6 Here, we investigate the role of Agrp neurons in the control of peripheral substrate utilization.

7 Our data demonstrate that Agrp neuron activation rapidly regulates peripheral metabolism

8 independently of food ingestion. Specifically, Agrp neuron activation promotes lipogenesis via

9 sympathetic nervous system (SNS). These results highlight the complex function of these key

10 hypothalamic neurons in normal physiology and in disordered metabolic states, such as obesity. 


\section{Results}

\section{$2 \quad$ Acute switch in nutrient utilization upon Agrp activation}

Nutrient utilization can be measured by indirect calorimetry, where the measurements of

$4 \quad \mathrm{VCO}_{2}$ production and $\mathrm{VO}_{2}$ consumption are used to calculate the respiratory exchange ratio

5 (RER) (Figure 1A) (Frayn, 1983). Under normal conditions, a RER approaching 0.7 indicates

6 predominant fat oxidation, while a RER approaching 1.0 indicates predominant carbohydrate

7 oxidation (Figure 1A) (Frayn, 1983). To test for the acute role of Agrp neurons in nutrient

8 utilization we took advantage of an animal model that we have recently characterized (Dietrich et

9 al., 2015; Ruan et al., 2014), in which Agrp neurons are transiently activated by peripheral

10 injection of capsaicin in $\operatorname{Agrp}^{\text {Trpv1 }}$ mice (Dietrich et al., 2015; Ruan et al., 2014). Agrp ${ }^{\text {Trpv1 }}$ mice

11 are generated by crossing $\operatorname{Agrp}^{\mathrm{Cre}}$ to $\operatorname{Rosa} 26^{\mathrm{LSL}-\mathrm{Trpv} 1}$ mice backcrossed to a $\operatorname{Trpv} 1^{\mathrm{KO}}$ background

12 to prevent capsaicin action on other cell types (Arenkiel et al., 2008; Guler et al., 2012). As a

13 result, Agrp $^{\text {Trpv1 }}$ mice selectively express the capsaicin-sensitive channel, Trpv1, in Agrp

14 neurons. Because capsaicin is a highly specific ligand of Trpv1 (Caterina et al., 1997), peripheral

15 injection of capsaicin allows for a rapid, reliable and transient chemogenetic activation of Agrp

16 neurons in Agrp $^{\text {Trpv1 }}$ mice (Dietrich et al., 2015; Ruan et al., 2014). Using Agrp $^{\text {Trpv1 }}$ mice allowed

17 us to rapidly activate Agrp neurons without the necessity of tethers (as for example, using

18 optogenetics), facilitating the study of animals in indirect calorimetry chambers to measure gas

$19\left(\mathrm{O}_{2}\right.$ and $\left.\mathrm{CO}_{2}\right)$ exchange. Importantly, Trpv1-mediated activation of Agrp neurons is both rapid

20 (latency to start is $\sim 2 \mathrm{~min}$ ) and short lived (lasts $\sim 1 \mathrm{~h}$ ), unlike the effects of activating Agrp

21 neurons via the designer receptor hM3Dq (Krashes et al., 2011).

We injected mice with capsaicin during the light cycle and recorded concomitant changes

23 in locomotor activity and gas exchange for the ensuing 24 hours. Capsaicin injections produced 
1 sharp increases in RER in $\operatorname{Agrp}^{\text {Trpv1 }}$ mice, (Figure 1B), in line with the previously observed fast

2 kinetics of feeding induced by Agrp neuronal activation in this animal model (Dietrich et al.,

3 2015). We did not observe statistically significant changes in either $\mathrm{VO}_{2}$ (Figure 1C), $\mathrm{VCO}_{2}$

4 (Figure 1D) or energy expenditure (Figure 1E). Because exercise increases RER, we also

5 measured activity levels upon Agrp neuron activation. In line with our previous report (Dietrich

6 et al., 2015), activation of Agrp neurons in the home cage in the presence of food did not

7 increase levels of ambulatory activity (Figure 1F), indicating that the increase in RER was not

8 affected by elevated locomotion. Based on gaseous exchange (Frayn, 1983), we calculated total

9 rates of fat utilization and carbohydrate utilization for the whole animal. In line with changes in

10 RER, activation of Agrp neurons led to a rapid and prolonged decrease in fat utilization (Figure

11 1G) concomitant with an increase in carbohydrate utilization (Figure 1H). Because (i) this

12 experiment was performed in the presence of food and (ii) the effects on nutrient utilization were

13 prolonged compared to feeding upon Agrp neuron activation (Dietrich et al., 2015), we

14 hypothesized that these metabolic shifts are due to changes in postprandial metabolism.

\section{Effects of diet ingestion on metabolic switches}

16 To further dissect the effects of altered RER from increased food intake upon Agrp

17 neuron activation, we determined how diet composition affects the metabolic phenotypes by

18 varying the proportion of macronutrients in the diet (Figure 2A; see Material and Methods for

19 more details). We activated Agrp neurons in $\operatorname{Agrp}^{\text {Trpv1 }}$ mice during the light cycle, providing

20 controlled amounts of different diets: LFHS, a low-fat high-sugar diet containing $10 \% \mathrm{kcal}$ from

21 fat sources; HF45, a high-fat diet containing 45\% kcal from fat sources; and HF60, a high-fat

22 diet containing $60 \% \mathrm{kcal}$ from fat sources. The three diets contain $20 \% \mathrm{kcal}$ from protein

23 sources. We performed these experiments in three different conditions: (i) limiting the amount of 
1 calories ingested from fat sources ( $0.4 \mathrm{kcal}$ from fat, 'Fat Clamp'); (ii) limiting the amount of

2 calories ingested from carbohydrate sources (0.7 kcal from sugars, 'Sugar Clamp'), or (iii)

3 feeding animals isocaloric quantities of food ( $1.5 \mathrm{kcal}$ from all sources, 'Cal Clamp').

4 Before activation of Agrp neurons, baseline RER was $0.79 \pm 0.003$ (mean \pm s.e.m.; $\mathrm{n}=$

590 measurements), fat utilization was $0.51 \pm 0.01 \mathrm{mg} \cdot \mathrm{min}^{-1}$ (mean \pm s.e.m.; $\mathrm{n}=90$

6 measurements) and carbohydrate utilization was $0.61 \pm 0.02 \mathrm{mg} \cdot \min ^{-1}$ (mean \pm s.e.m.; $\mathrm{n}=90$

7 measurements), indicating that in the conditions tested animals were using substrates from mixed

8 sources. Following activation of Agrp neurons, we observed an increase in RER in all conditions

9 tested (Figure 2B and Figure 2 - Figure supplement 1A). In linear regression analyses, we

10 found a strong correlation between RER and carbohydrate ingestion $\left(\mathrm{r}^{2}=0.85, P<0.001\right)$, but

11 not protein $\left(\mathrm{r}^{2}=0.30, P=0.12\right)$ or fat $\left(\mathrm{r}^{2}=0.12, P=0.35\right)$ (Figure 2C). Fat utilization was

12 reduced upon Agrp neuron activation in all conditions tested (Figure 2D and Figure 2 - Figure

13 supplement 1 F) and was negatively correlated with carbohydrate ingestion $\left(\mathrm{r}^{2}=0.85, P<\right.$

$140.001)$, but not protein $\left(r^{2}=0.26, P=0.15\right)$ or fat $\left(r^{2}=0.16, P=0.25\right)$ (Figure 2E).

15 Carbohydrate utilization followed changes in RER, increasing upon Agrp neuron activation in all

16 dietary conditions tested (Figure 2F and Figure 2 - Figure supplement 1G). Changes in

17 carbohydrate utilization were strongly correlated to carbohydrate ingestion $\left(\mathrm{r}^{2}=0.90, P<\right.$

18 0.0001; Figure 2G). Protein ingestion also correlated with carbohydrate utilization, but linear

19 regression analysis did not reach statistical significance $\left(r^{2}=0.39, P=0.07\right.$; Figure 2G). Fat

20 intake did not correlate with carbohydrate utilization $\left(\mathrm{r}^{2}=0.07, P=0.46\right.$; Figure 2G). As

21 expected, these results demonstrated that carbohydrate levels in the diet are main players in the

22 metabolic shift that occurs upon food ingestion, suggesting that macronutrient quality rather than

23 caloric content account for these effects. 


\section{Agrp neurons control substrate utilization in the absence of ingestion}

The effect of Agrp neuron activation on carbohydrate metabolism led us to further

3 explore the extent to which activation of Agrp neurons and sugar ingestion interact to rapidly

4 shift metabolism. We provided different concentrations of glucose to mice via gavage delivery,

5 thereby ruling out potential cephalic phase effects (Figure 3A). Gavage infusion of glucose led

6 to dose-dependent increases in RER (Figure 3B; $\mathrm{r}^{2}=0.99, P=0.003$ ), decreases in fat utilization

$7 \quad$ (Figure 3C; $\left.\mathrm{r}^{2}=0.99, P=0.004\right)$, and increases in carbohydrate utilization (Figure 3D; $\mathrm{r}^{2}=$

$80.99, P=0.003)$. These metabolic shifts were mainly due to increases in $\mathrm{VCO}_{2}\left(\right.$ Figure $3 \mathbf{F} ; \mathrm{r}^{2}=$

$90.98, P=0.006)$ and not $\mathrm{VO}_{2}\left(\right.$ Figure $\left.3 \mathrm{E} ; \mathrm{r}^{2}=0.84, P=0.07\right)$. Glucose intake also positively

10 correlated with energy expenditure (Figure 3G; $r^{2}=0.92, P=0.03$ ), likely due to the thermic

11 effects of carbohydrate digestion. Activity levels were unchanged (Figure 3D; $\mathrm{r}^{2}=0.58, P=$

12 0.23). These experiments demonstrate that small amounts of carbohydrate ingestion alone are

13 sufficient to shift metabolism even in the absence of carbohydrate sensing at the level of the

14 mouth. Thus, our previous results on substrate metabolism upon activation of Agrp neurons

15 could be simply explained by ingestion of carbohydrates. We designed the next experiments to

16 test this consideration.

17 We infused both control and $\operatorname{Agrp}^{\text {Trpv1 }}$ mice with glucose $(2 \mathrm{~g} / \mathrm{kg}$ body weight, via

18 gavage) and activated Agrp neurons by injecting capsaicin (Figure 4A). Strikingly, activation of

19 Agrp neurons led to an increased peak and a more sustained elevation of RER (Figure 4B), an

20 effect that was present even in mice infused with saline (Figure 4B). Accordingly, activation of

21 Agrp neurons led to a sustained decrease in fat utilization (Figure 4C) and increase in

22 carbohydrate utilization (Figure 4D), regardless of glucose infusion. These results strongly

23 suggest that activation of Agrp neurons alone is sufficient to promote shifts in substrate 
1 utilization, independently of food consumption. However, even in animals infused with saline,

2 small amounts of liquid were delivered via gavage, raising the possibility that gastric distension

3 acts together with Agrp neuron activation to promote changes in substrate utilization. To exclude

4 this possibility, we repeated our experiments in a new cohort of mice in which Agrp neurons

5 were activated in the absence of food (Figure 4 supplement 1A). In line with our previous

6 findings, activation of Agrp neurons alone was sufficient to increase RER (Figure 4 supplement

7 1B), while decreasing fat utilization (Figure 4 supplement 1G) and increasing carbohydrate

8 utilization (Figure 4 supplement 1H). The above experiments demonstrate that Agrp neurons

9 rapidly control whole body substrate utilization by shifting metabolism towards carbohydrate

10 relative to fat utilization independently of ingestive behaviors.

\section{Participation of lipogenesis in Agrp neuron-mediated shifts in metabolism}

12 A physiological scenario in which the metabolic shift promoted by Agrp neuron

13 activation is expected to be important is during positive energy balance (i.e., a metabolic state

14 coupled to weight gain), as favoring carbohydrate utilization would allow storage of lipids and

15 re-route of energy substrates to undergo de novo lipogenesis, further increasing fat deposition. In

16 line with this, we found that, in absence of food ingestion, Agrp neuron activation decreased

17 circulating levels of non-esterified fatty acids (NEFAs, Figure 5B) with no changes in blood

18 glucose levels (Figure 5C) in well-fed mice (Figure 5A). Because circulating NEFAs decrease

19 upon Agrp neuron activation, these results suggest a decrease in release, and possibly an increase

20 in deposition. To test this hypothesis, we measured expression levels of genes involved in lipid

21 metabolism in the white adipose tissue (WAT) from $\operatorname{Agrp}^{\text {Trpv1 }}$ and control mice 60 minutes after

22 capsaicin injection. We found a decrease in the expression level of Ppara (Figure 5D), a gene

23 involved in the promotion of fat catabolism. We also found a significant increase in expression 
1 levels of hexokinase2 ( $h k 2$; Figure 5D), a rate-limiting enzyme involved in glycolysis, a critical

2 metabolic step to provide carbons for de novo lipogenesis. Hormone-sensitive lipase (HSL) is an

3 essential step in the breakdown of triglycerides to release fatty acids in circulation. Activation of

4 HSP occurs by phosphorylation of this enzyme in several serine residues. Upon activation of

5 Agrp neurons, we found decreased levels of phosphorylated HSL (pHSL) in WAT compartments

6 (Figure 5E). Together, these experiments indicate activation of Agrp neurons leads to increased

7 lipogenesis and decreased lipolysis in the WAT.

8 De novo lipogenesis can drive RER above 1.0 (Frayn, 1983), and could be a potential

9 factor involved in Agrp neuron mediated acute shifts in RER. Additionally, in our dietary clamp

10 experiments (Figure 2), we found negative results for fat utilization in mice that ate large

11 amounts of sugars (Figure 2 supplement 1F). Because calculated fat utilization is the sum of

12 true rates of fat oxidation minus the rate of synthesis of fat from carbohydrates (de novo

13 lipogenesis) (Frayn, 1983), an increase in synthesis leads to a net decrease in calculated fat

14 utilization. Thus, negative values for calculated fat utilization only occur when the rate of

15 synthesis is higher than the rate of oxidation (Frayn, 1983), and are pathognomonic of ongoing

16 lipid synthesis. To test for the participation of fat synthesis in the rapid effects of Agrp neurons

17 on metabolism, we blocked fatty acid synthetase (FAS), a key enzyme involved in fat storage

18 (Lodhi et al., 2012). We treated mice with a pharmacological inhibitor of FAS (C75, $10 \mathrm{mg} / \mathrm{kg}$,

19 i.p.) (Kuhajda et al., 2000; Loftus et al., 2000) and activated Agrp neurons in indirect calorimetry

20 chambers (Figure 5F). Treatment of control mice with the FAS inhibitor had no effects on RER

21 (Figure 5G), fat utilization (Figure 5H) or carbohydrate utilization (Figure 5I). The lack of

22 effects of FAS inhibition on substrate utilization is in line with the low levels of lipogenesis

23 during the light cycle of mice. In contrast to control animals, inhibition of FAS blocked the 
1 effects of Agrp neuron activation on substrate utilization (Figures 5G-I). These results

2 demonstrate Agrp neurons rapidly shift metabolism towards lipogenesis in well-fed animals.

3 Sympathetic signaling mediates peripheral effects of Agrp neurons

4 We next determined if Agrp neurons control peripheral substrate utilization via SNS

5 signaling. Norepinephrine release and binding to adrenergic receptors on fat compartments

6 promotes lipolysis, while its inhibition favors lipogenesis. Accordingly, we predicted that Agrp

7 neurons control adiposity by inhibiting sympathetic signaling on fat compartments and

8 promoting lipogenesis in anabolic states. To test for this hypothesis, we treated mice with a 33 -

9 adrenergic receptor agonist (CL 316,243) (Bloom et al., 1992) (Figure 6A), as B3-adrenergic

10 receptors are highly selective to fat compartments (Grujic et al., 1997). Treatment of control

11 mice with CL 316,243 did not alter RER (Figure 6B), but prevented the increase in RER upon

12 Agrp neuron activation in $\operatorname{Agrp}^{\text {Trpv1 }}$ mice (Figure 6B). When we calculated fat utilization, CL

13316,243 completely reverted the inhibition of whole body fat utilization upon Agrp neuron

14 activation in $\mathrm{Agrp}^{\mathrm{Trpv} 1}$ mice but had no effects in control animals (Figure 6C). Concomitantly,

15 CL 316,243 prevented the increase in carbohydrate utilization upon activation of Agrp neurons

16 (Figure 6D). These results demonstrate that promotion of $\beta 3$-adrenergic receptor signaling in fat

17 compartments is sufficient to revert the effects of Agrp neurons on peripheral fuel metabolism.

18 Because Agrp neurons are characteristically linked to food intake control (Aponte et al.,

19 2011; Gropp et al., 2005; Hahn et al., 1998; Krashes et al., 2011; Luquet et al., 2005; Rossi et al.,

20 1998), we investigated whether the effects of Agrp neurons on fuel utilization are

21 mechanistically linked to feeding. Thus, we tested whether CL 316,243 could acutely block the

22 effects of Agrp neuron activation on food intake. We first performed a dose response study to

23 detect the range of CL 316,243 doses that could revert the increase in RER upon Agrp neuron 
1 activation. We found that doses as low as $0.01 \mathrm{mg} / \mathrm{kg}$ almost completely reverted the effects of

2 Agrp neurons on RER (Figure 6E). Next, we selected two doses of CL 316,243 (1.00 and 0.01

$3 \mathrm{mg} / \mathrm{kg}$ ) to investigate its effects on Agrp neuron mediated food intake. CL 316,243 is highly

4 anorexigenic (Grujic et al., 1997), but its effects are observed after several hours and not as rapid

5 as the effects of Agrp neurons on feeding (Aponte et al., 2011; Dietrich et al., 2015; Krashes et

6 al., 2011). In all conditions tested, CL 316,243 did not revert the effects of Agrp neuron

7 activation on food intake (Figures 6F-G). These latter findings indicate a divergence between

8 the feeding and metabolic mechanisms underlying Agrp neuron function and support the

9 argument that Agrp neurons favor the storage of fat (lipogenesis) in situations of energy surfeit

10 (Figure 6H). 


\section{Discussion}

We reported here a mechanism by which elevated Agrp neuron activity shifts metabolism

3 towards lipid storage via the SNS. The SNS releases norepinephrine in target organs to regulate a

4 variety of physiological functions. In WAT, which stores excess of energy in the form of fat,

5 activation of the SNS leads to lipolysis (Bartness et al., 2014; Correll, 1963; Zeng et al., 2015),

6 breaking down triglycerides to release free fatty acids in the circulation (Zeng et al., 2015).

7 Lipolysis is critical for survival during periods of food scarcity, with fatty acids becoming the

8 predominant energy substrate. Conversely, inhibition of lipolysis favors lipogenesis, leading to

9 fat deposition (Rutkowski et al., 2015). This is an important adaptive response to allow storage

10 of the excess of energy for later mobilization during food deprivation. However, when this

11 anabolic state (lipogenesis > lipolysis) is sustained it can become maladaptive and trigger

12 obesity. Here, we provided evidence that elevated activity of Agrp neurons is sufficient to

13 promote this shift in metabolism towards storage of nutrients (largely carbohydrates) as fat.

14 Our results are in apparent contrast with a previous publication showing that neonatal

15 ablation of Agrp neurons leads to decreased RER, increased metabolic efficiency and obesity in

16 adult animals (Joly-Amado et al., 2012). Contrary to adult ablation of Agrp neurons which leads

17 to cessation of feeding and death (Gropp et al., 2005; Luquet et al., 2005; Wu and Palmiter,

18 2011), neonatal ablation of these neurons is compatible with life (Luquet et al., 2005). In the

19 study by (Joly-Amado et al., 2012), Agrp neurons were ablated during the first postnatal week.

20 The authors found Agrp neuron-ablated mice presented metabolic abnormalities only later in

21 adulthood ( $>3$ months of age), which were in similar direction to acute activation of Agrp

22 neurons in adult animals (this report and (Srisai, 2016; Steculorum et al., 2016)). These results

23 strengthen the idea that Agrp neurons have distinct roles at different developmental stages 
1 (Dietrich et al., 2012), and that altering the function of Agrp neurons early in life leads to

2 compensatory mechanisms with long lasting physiological implications.

Recent studies have described the in vivo dynamics of Agrp neuron activity (Betley et al.,

4 2015; Chen et al., 2015; Mandelblat-Cerf et al., 2015). However, not all cells were homogeneous

5 in their response. While 2/3 of Agrp neurons had decreased activity upon presentation of

6 food/eating, the other third did not change firing rate or even increased activity during eating.

7 The fact that Agrp neurons had heterogeneous response to feeding further highlights the

8 existence of subpopulations of Agrp neurons that are functionally, anatomically (Betley et al.,

9 2013; Padilla et al., 2016; Steculorum et al., 2016), and potentially genetically distinct. In light of

10 our data, it is thus possible that the sustained activity of distinct subpopulation of Agrp neurons

11 during feeding/refeeding might operate to maximize energy storage by shifting substrate

12 utilization towards lipogenesis.

13 Less expected than the elevated activity of Agrp neurons during food deprivation were

14 the findings that during diet-induced obesity (DIO) the activity of these neurons is also elevated

15 (Baver et al., 2014; Diano et al., 2011; Dietrich et al., 2013; Wei et al., 2015). In a previous

16 study, we have identified that the elevated activity of Agrp neurons during high-fat feeding relies

17 on intracellular mitochondria fusion machinery (Dietrich et al., 2013). We found that deletion of

18 mitofusins selectively in Agrp neurons was sufficient to blunt the increase in neuronal activity in

19 response to a high-fat diet (HFD); as a consequence, mice were resistant to DIO. Intriguingly, we

20 found only minor or no effects of these genetic manipulations on food intake (Dietrich et al.,

21 2013), indicating that, in obesogenic conditions, Agrp neurons also control other aspects of

22 physiology that are independent of food consumption. The elevated activity of Agrp neurons

23 during obesity development (Baver et al., 2014; Diano et al., 2011; Dietrich et al., 2013; Wei et 
1 al., 2015) could be involved in the metabolic shifts towards fat deposition (lipogenesis) as

2 observed here. This consideration, however, will require further testing in future studies.

3 In summary, we showed that Agrp neurons in the hypothalamus rapidly control whole-

4 body nutrient utilization by shifting metabolism towards lipogenesis via the sympathetic nervous

5 system. These studies expanded the repertoire of functions attributed to Agrp neurons, which

6 emerge as controllers of a variety of physiological functions in addition to food intake. Because

7 there are several thousands of Agrp neurons in the mammalian brain, future studies will be

8 important to determine whether each subpopulation of Agrp neurons regulate a specific

9 physiological function. Because Agrp neurons release several molecules, including AGRP, NPY,

10 and GABA, it is also possible that this multifaceted function of Agrp neurons arises from the

11 combination of released molecules. These findings have strong implications for our

12 understanding of how neuronal circuits involved in metabolism regulation function and,

13 consequently, to our understanding of severe disordered conditions such as obesity. 


\section{Experimental Procedures}

\section{Animals}

$3 \quad$ Mice used in the experiments were 3-8 months old from both genders. Agrp $^{\text {Trpv1 }}$ mice 4 were: $\operatorname{Agrp}^{\mathrm{Cre} /+}:: \operatorname{Trpv1} 1^{\mathrm{KO} / \mathrm{KO}}:: R 26-L S L-\operatorname{Trpv} 1^{\mathrm{Gt} /+}$; control animals were either $\operatorname{Agrp}^{\mathrm{Trpv} 1}$ mice

5 injected with vehicle (3.3\% Tween 80 in saline) or $\operatorname{Trp} v 1^{\mathrm{KO} / \mathrm{KO}}: R 26-L S L-\operatorname{Trp} v 1^{\mathrm{Gt} /+}$ mice injected

6 with capsaicin. All animals were littermates (Agrp neuron activated and controls) in the

7 experiments. We did not observe any differences between the two control groups and, therefore,

8 throughout the manuscript we referred to them as "controls". We have carefully characterized

9 this animal model to activate Agrp neurons and reported elsewhere (Dietrich et al., 2015; Ruan et

10 al., 2014). We have performed dose-response curves for capsaicin and identified the dose of 10

$11 \mathrm{mg} / \mathrm{kg}$ (i.p.) as optimal to induce behavior phenotypes in ggrp $^{\text {Trpv1 }}$ mice. We have also

12 performed a dose-response of capsaicin and measured changes in RER (1, 3, 10 and $30 \mathrm{mg} / \mathrm{kg}$,

13 i.p.; experiments not reported). We also found that $10 \mathrm{mg} / \mathrm{kg}$ was the optimal dose to promote

14 changes in RER. Thus, we selected this dose of capsaicin for our studies.

15 The following mouse lines were used in this study: Agrptm1(cre)Lowl/J,

16 Gt(ROSA)26Sortm1(Trpv1,ECFP)Mde/J, Trpv1tm1Jul/J. These lines are available from The

17 Jackson laboratories. All animals were kept in temperature and humidity controlled rooms, in a

18 12/12h light/dark cycle, with lights on from 7:00AM-7:00PM. Food and water were provided ad

19 libitum, unless otherwise stated. All procedures were approved by IACUC (Yale University).

\section{Drugs}

The following compounds were used in the reported studies: C75 (RPMI medium 1640;

22 from Tocris); capsaicin (3.3\% Tween-80 in saline; from Sigma), and CL-316, 245 (in PBS; from 
1 Tocris). All drugs were injected in a volume of $10 \mathrm{ml} / \mathrm{kg}$ of body weight intraperitoneally (i.p.).

2 When multiple injections were performed in the same experiment, the volume of each injection

3 was adjusted to a total volume of $10 \mathrm{ml} / \mathrm{kg}$ per animal.

\section{$4 \quad$ Metabolic Assays and Biochemical Analysis}

$5 \quad$ For all experiments animals were housed in individual cages at least three days prior to

6 the experiment. Blood samples were collected from the tail in order to measure glucose and free

7 fatty acids (NEFA) levels. Glucose was measured using a One Touch Ultra 2 glucometer. After

8 blood centrifugation, serum was collected and used to measure NEFA as indicated by

9 manufacturer (WAKO, Japan).

\section{Gene Expression and Western blotting}

12 Animals were deeply anesthetized with ketamine and xylazine and euthanized by

13 decapitation. Tissues were collected and frozen in liquid nitrogen. Tissues were lysed in buffer

14 containing 1\% Nonidet P-40, $50 \mathrm{mM}$ Tris $3 \mathrm{HCl}, 0.1 \mathrm{mM}$ EDTA, $150 \mathrm{mM} \mathrm{NaCl}$, proteinase

15 inhibitors and protein phosphatase inhibitors. Equal amounts of protein lysate were

16 electrophoresed on SDS-PAGE gels and transferred to PVDF membranes. Primary antibodies

17 (Lipolysis Activation Antibody Sampler Kit \#8334, Cell Signaling) were incubated at $4^{\circ} \mathrm{C}$

18 overnight. Membranes were washed and incubated with secondary antibodies conjugated to

19 horseradish peroxidase. Protein levels were visualized using ECL chemiluminescent substrate

20 and quantified using ImageJ.

21 Total RNA was extracted from mouse tissues using RNeasy® lipid mini kit (Qiagen).

22 cDNA was reverse transcribed (Bio-Rad) and amplified with SYBR Green Supermix (Bio-Rad) 
1 using a Light Cycler 480 real-time PCR system (Roche). Data were normalized to the expression

2 of Actin, Gusb and Arbp. Primer sequences are available on request.

Indirect calorimetry

Oxygen consumption $\left(\mathrm{VO}_{2}\right)$ and $\mathrm{CO}_{2}$ production $\left(\mathrm{VCO}_{2}\right)$ were measured in four to eight mice simultaneously in indirect calorimetry chambers (TSE Systems, Germany). Measurements were recorded every 8-12 minutes over the entire course of the experiment (except for the experiment in which ad libitum food intake was measured during one entire day). Respiratory exchange ratio (RER) was calculated as the ratio between $\mathrm{VCO}_{2}$ and $\mathrm{VO}_{2}$. Whole body fat

9 utilization was calculated using the follow equation: $1.67 *\left(\mathrm{VO}_{2}-\mathrm{VCO}_{2}\right)$. Whole body

10 carbohydrate utilization was calculate using the follow equation: $4.55 * \mathrm{VCO}_{2}-3.21 * \mathrm{VO}_{2}$

11 (Frayn, 1983). All animals were single housed during the experiments in calorimetry chambers.

12 For the experiments in which different diets were fed to the animals, the following diets were

13 used: low-fat high-sugar diet (LFHS; D12450B, Open Source Diets, USA); high-fat diet 45\%

14 calories from fat (HF45; D12451, Open Source Diets, USA); and high-fat diet 60\% calories from

15 fat (HF60; D12492, Open Source Diets, USA). For the glucose response study, mice were

16 provided with glucose (D-Glucose, G8270, Sigma, USA) via gavage. We used saline as vehicle

17 and three doses of glucose (1, 2 and $3 \mathrm{~g} / \mathrm{kg}$ body weight, via gavage feeding). Food was removed

182 hours before the experiment during the light cycle of the animals. Calorimetry was recorded

19 during 60 minutes prior injection of capsaicin and diet switch. For the experiments that no food

20 was provided, food was removed from the cages 2 hours before injecting mice with

21 capsaicin/vehicle. Baseline calorimetry was recorded for 60 minutes, and then the effects of

22 Agrp neuron activation were recorded for 60-120 minutes. Similar procedures were used in the

23 experiments in which compounds were given to mice prior the experiment. Glucose ( $2 \mathrm{~g} / \mathrm{kg}$, via 
1 gavage), C75 (10 mg/kg, i.p.) or CL-316,243 (0.01-1.00 mg/kg, i.p) were given together with

2 capsaicin. In all cases, the drugs were injected immediately before capsaicin using two different

3 syringes. Total injected volume was adjusted for the maximal dose of $10 \mathrm{ml} / \mathrm{kg}$ mouse body

4 weight.

\section{$5 \quad$ Statistical Considerations}

Matlab R2016a, PASW Statistics 18.0, Prism 7.0 and Adobe Illustrator CS6/CC were

$7 \quad$ used to analyze data and plot figures. Student's $t$ test was used to compare two groups. ANOVA

8 was used to compare multiple groups. When necessary, multiple comparisons post hoc test

9 (MCT) was used (Holm-Sidak's test). When homogeneity was not assumed, the Kruskal-Wallis

10 nonparametric ANOVA was selected for multiple statistical comparisons. The Mann-Whitney U

11 test was used to determine significance between groups. Statistical data are provided in the

12 figures. $P<0.05$ was considered statistically significant. 


\section{Acknowledgments}

2 We thank Matthew Rodeheffer, Ivan de Araujo, Hai-bin Ruan and Xiaoyong Yang for comments

3 on this project and manuscript. M.O.D. received support from Brain and Behavior Research

4 Foundation (NARSAD Young Investigator Award), Yale Center for Clinical Investigation

5 Scholars Award (NCATS, UL1 TR000142), National Institute Of Diabetes And Digestive And

6 Kidney Diseases (1R01DK107916-01), DRC (P30 DK045735), Whitehall Foundation, Charles

7 H. Hood Foundation, CNPq (487096/2013-4 and 401476/2012-0, Brazil) and CAPES

8 (88881.068059/2014-01, Brazil). JPA and MRZ were partially supported by a fellowship from

9 the Science Without Borders program (Brazil).

\section{Author Contributions}

$12 \mathrm{JB}$ and MZ helped to perform the experiments and analyze the data. JAP and MOD performed

13 the experiments, designed, analyzed data and wrote the manuscript. 
Figure 1

A

$$
\begin{aligned}
& \mathrm{RER}=\frac{\dot{\mathrm{V}} \mathrm{CO}_{2}}{\dot{\mathrm{V}} \mathrm{O}_{2}} \\
& \begin{array}{l}
0.7 \\
\text { Fat }
\end{array} \text { Carb. }
\end{aligned}
$$

B

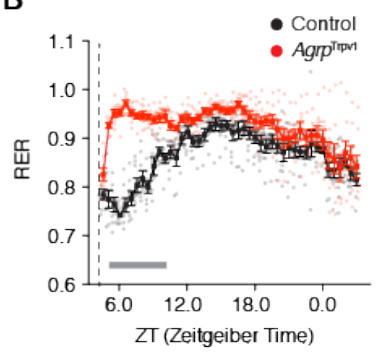

E

1

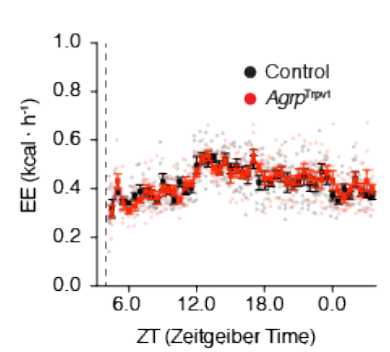

$\mathbf{F}$

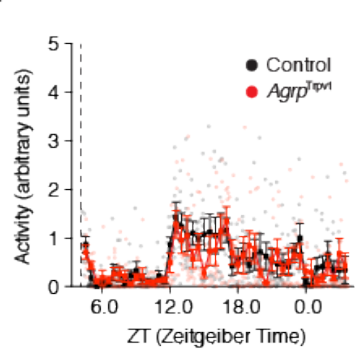

C

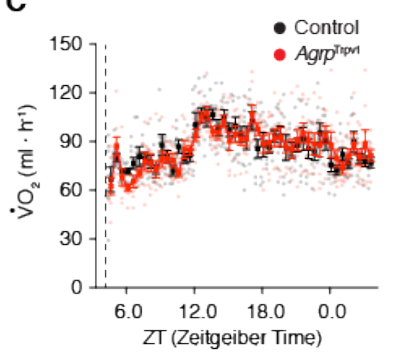

G

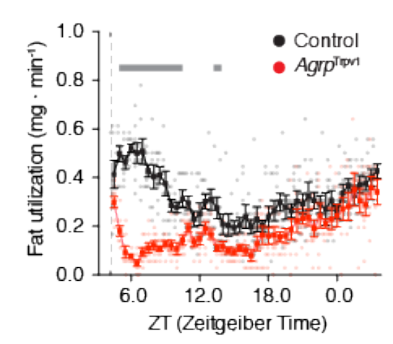

D

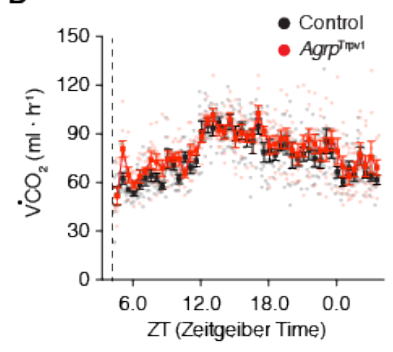

$\mathrm{H}$

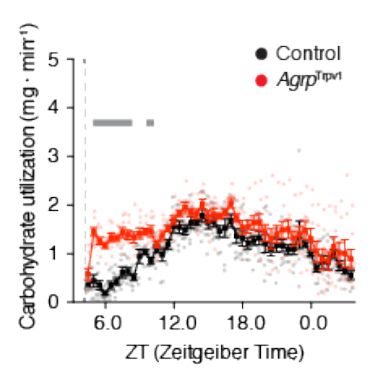

2 Figure 1: Rapid shift in substrate utilization upon activation of Agrp neurons.

3 (A) In indirect calorimetry chambers, RER was calculated by diving the $\mathrm{VCO}_{2}$ by the $\mathrm{VO}_{2}$;

4 oxidation of fat acids (e.g., palmitate) generates a RER of 0.7 , while oxidation of carbohydrates

5 (e.g., glucose) generates a RER of 1.0. From B-H, control (black; $\mathrm{n}=8$ ) and Agrp $^{\text {Trpv1 }}$ mice (red;

$6 \mathrm{n}=8$ ) were acclimated to calorimetry chambers before been injected with capsaicin (dashed

7 lines; $10 \mathrm{mg} / \mathrm{kg}$, i.p.) during the light cycle with food and water provided ad libitum. (B) RER

8 (interaction: $F_{45,630}=8.40, P<0.0001$; time: $F_{45,630}=13.86, P<0.0001$; group: $F_{1,14}=52.59, P$

$9<0.0001$ ). (C) $\mathrm{VO}_{2}$ (interaction: $F_{45,630}=1.07, P=0.34$; time: $F_{45,630}=11.22, P<0.0001$;

10 group: $F_{1,14}=0.01, P=0.89$ ). (D) $\mathrm{VCO}_{2}$ (interaction: $F_{45,630}=0.88, P=0.68$; time: $F_{45,630}=$

11 15.07, $P<0.0001$; group: $\left.F_{1,14}=1.58, P=0.22\right)$. (E) Energy expenditure (interaction: $F_{45,630}=$

$120.96, P=0.53$; time: $F_{45,630}=12.09, P<0.0001$; group: $\left.F_{1,14}=0.02, P=0.87\right)$. (F) Ambulatory

13 activity (interaction: $F_{45,630}=0.80, P=0.81$; time: $F_{45,630}=6.02, P<0.0001$; group: $F_{1,14}=$

$140.31, P=0.58$ ). (G) Calculated fat utilization (interaction: $F_{45,630}=6.44, P<0.001$; time: $F_{45,630}$

$15=7.22, P<0.0001$; group: $F_{1,14}=33.83, P<0.0001$ ). (H) Calculated carbohydrate utilization 
1 (interaction: $F_{45,630}=2.77, P<0.0001$; time: $F_{45,630}=18.48, P<0.0001$; group: $F_{1,14}=16.73, P$

$2=0.001)$. Statistical analysis was performed using two-way ANOVA with time as a repeated

3 measure followed by Holm-Sidak's multiple comparisons test (MCT). Grey bars indicate time

4 points in which MCTs were statistically significant $(P<0.05)$. Dashed line indicates time of

5 capsaicin injection. Small symbols indicate individual values. Large symbols indicate mean \pm

6 SEM. 
Figure 2
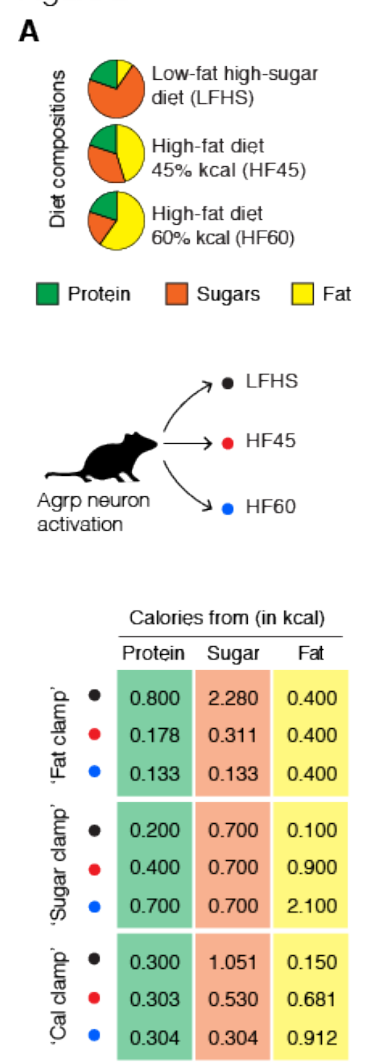

2 Figure 2: Substrate utilization in response to different diets.

3 Mice $\left(\right.$ Agrp $\left.^{\text {Trpv1 }}\right)$ were tested in calorimetry chambers for their rapid response to different diets

4 upon activation of Agrp neurons (with capsaicin, $10 \mathrm{mg} / \mathrm{kg}$, i.p). (A) Three different diets were used in the studies, containing different distribution of macronutrients from similar sources

6 (protein levels were equal at $20 \mathrm{kcal} \%$ ); low-fat high-sugar diet (LFHS; Research Diets

7 D12450B [carbohydrates: $70 \mathrm{kcal} \%$; fat: $10 \mathrm{kcal} \%$ ]); high-fat diet (HF45; Research Diets three different diets in three different experimental conditions (see table; $\mathrm{n}=10$ mice per

11 condition): 'Fat clamp', all mice received a pellet of the diet containing 0.4 kcal from fat; 'Sugar

12 clamp', mice received a food pellet containing $0.7 \mathrm{kcal}$ from carbohydrates; and 'Cal clamp', 
1 mice received a food pellet containing a total of $1.5 \mathrm{kcal}$ from all sources. (B) Mean RER after

2 activation of Agrp neurons (related to Figure 2 supplement 1A): 'Fat clamp' $\left(F_{2,27}=29.13, P<\right.$

3 0.0001); 'Sugar clamp' $\left(F_{2,27}=2.662, P=0.08\right)$, and 'Cal clamp' $\left(F_{2,27}=4.753, P=0.01\right) .(\mathbf{C})$

4 Correlation between RER (abscissa) and macronutrient intake (ordinate). (D) Mean calculated fat

5 utilization after activation of Agrp neurons (related to Figure 2 supplement 1F): 'Fat clamp' $\left(F_{2}\right.$,

$\left.6{ }_{27}=16.5, P<0.0001\right)$; 'Sugar clamp' $\left(F_{2,27}=2.878, P=0.07\right)$, and 'Cal clamp' $\left(F_{2,27}=8.897, P\right.$

$7=0.001)$. (E) Correlation between fat utilization (abscissa) and macronutrient intake (ordinate).

8 (F) Mean calculated carbohydrate utilization after activation of Agrp neurons (related to Figure 2

9 supplement $1 \mathrm{G})$ : 'Fat clamp' $\left(F_{2,27}=45.83, P<0.0001\right)$; 'Sugar clamp' $\left(F_{2,27}=2.627, P=\right.$

10 0.09), and 'Cal clamp' $\left(F_{2,27}=5.53, P=0.009\right)$. (G) Correlation between carbohydrate

11 utilization (abscissa) and macronutrient intake (ordinate). In B, D and F, ordinary one-way

12 ANOVA was used to test for statistical differences within each experimental condition ('Clamp')

13 followed by Holm-Sidak's multiple comparisons test (MCT). MCTs are indicated as * $P<0.05$,

$14 * * P<0.01, * * * P<0.001$, and $* * * * P<0.0001$. Large symbols indicate mean $\pm \mathrm{SEM}$. Small

15 grey symbols indicate individual values. Ten mice were used per condition. In $\mathrm{C}$, E, and $\mathrm{G}$,

16 linear regression analysis was used to calculate the correlation between total macronutrient

17 intake and substrate utilization measurements (as plotted in B, D, and F); each point represents

18 the mean response of 10 animals in the same condition (from $\mathrm{B}, \mathrm{D}$, and $\mathrm{F}$ ); $r^{2}$ and $P$ values are

19 plotted in each panel; dashed red line represents the linear regression model. Figure 2

20 supplement 1 presents detailed analysis of the calorimetry data and activity levels. 
Figure 2 supplement 1

A

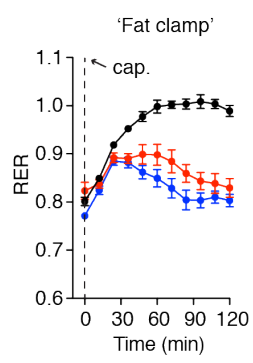

C

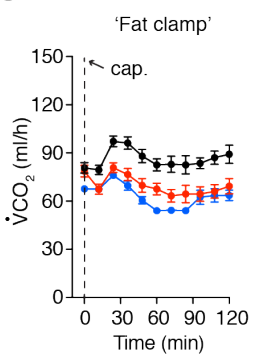

E

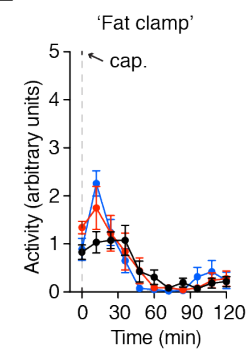

G

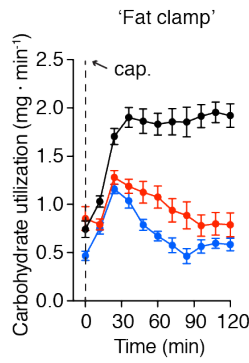

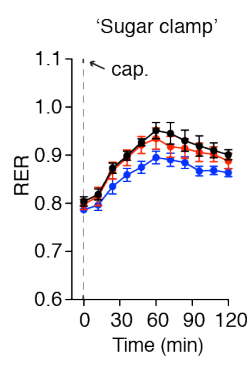
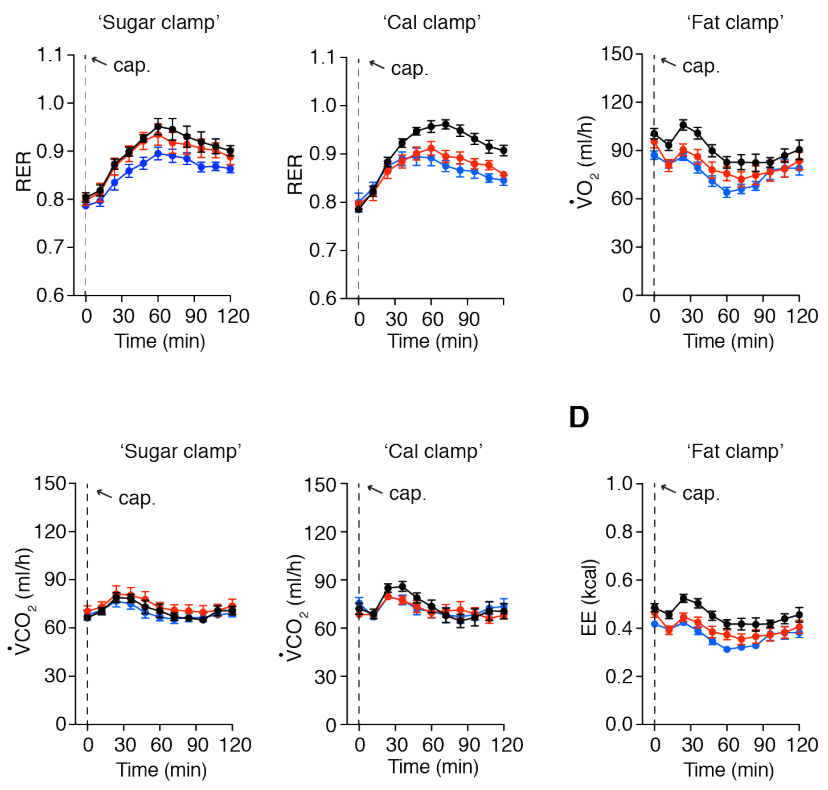

$\mathbf{F}$
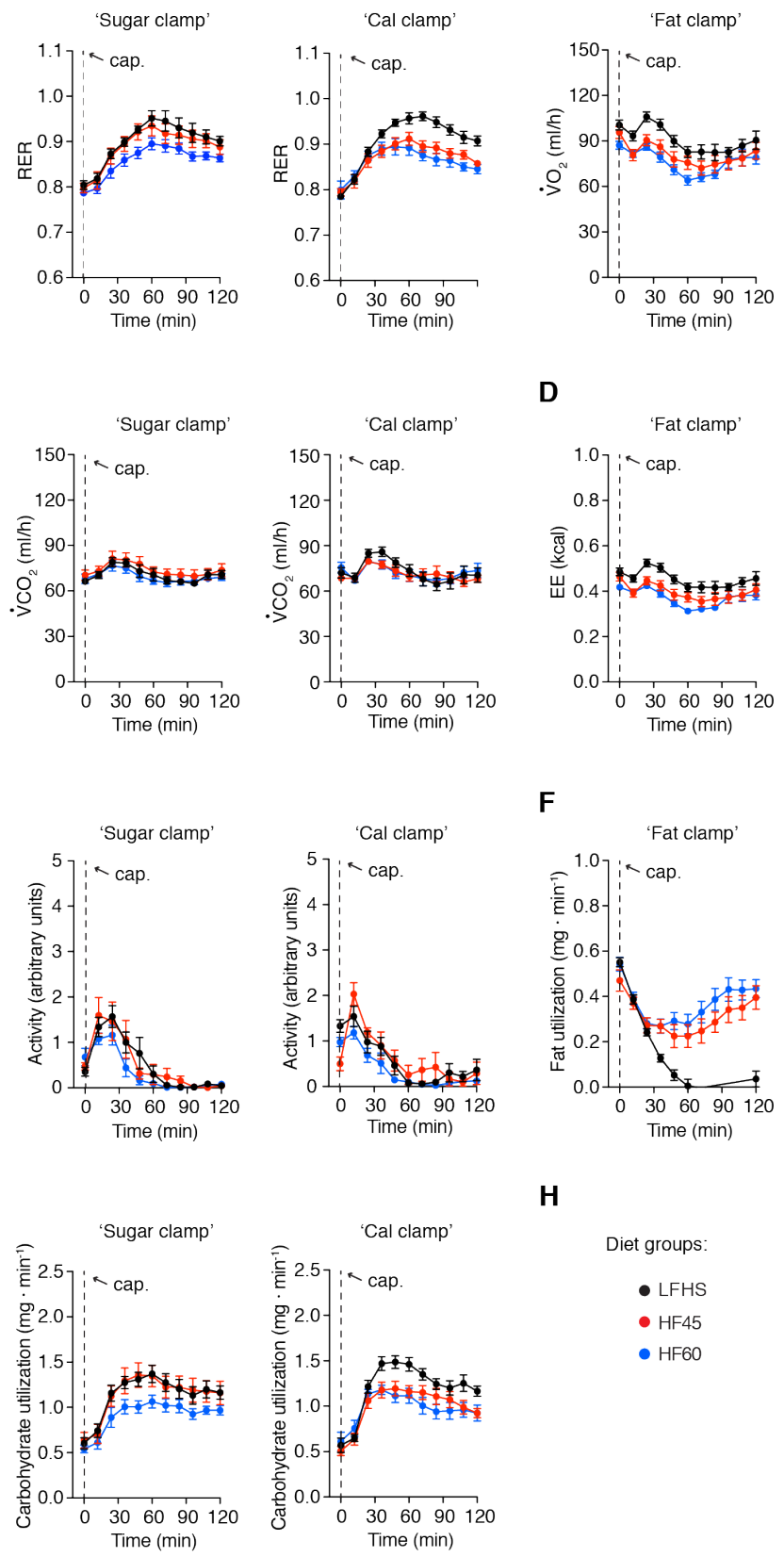

H

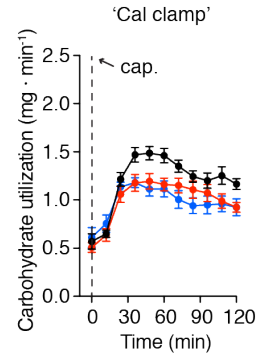

Diet groups:

- LFHS

- HF45

- HF60
B
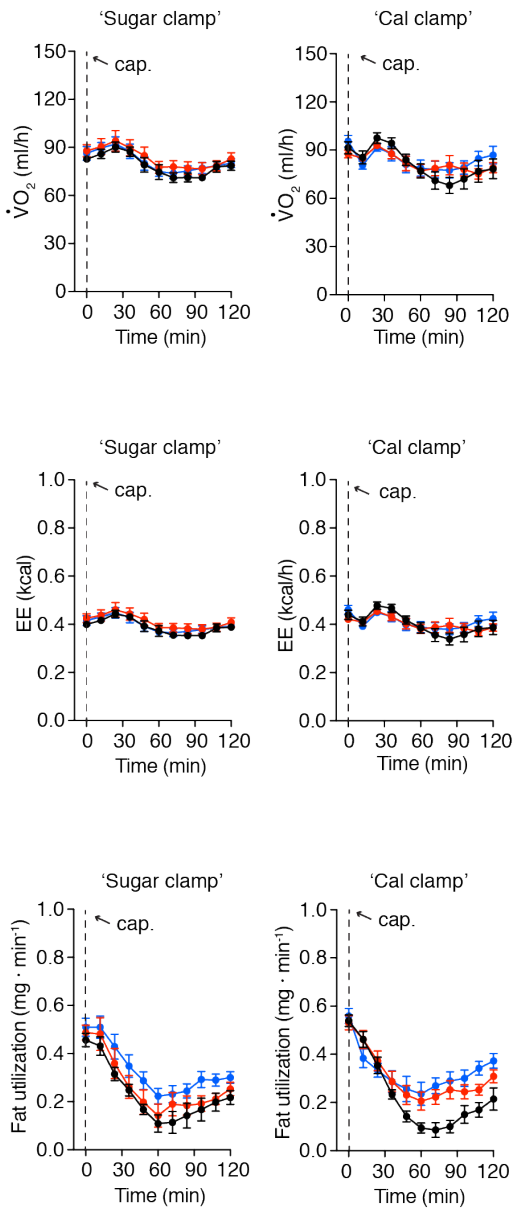

Figure 2 supplement 1: Substrate utilization in response to different diets.

3 Detailed metabolic phenotyping data of $\operatorname{Agrp}^{\text {Trpv1 }}$ mice fed different diets (Figure 2A) upon

4 activation of Agrp neurons by peripheral injection of capsaicin (10 mg/kg, i.p.). In black, mice

5 fed a low-fat high-sugar diet (LFHS; Research Diets D12450B); in red, mice fed a high-fat diet

6 (45 kcal\% from fat, HF45; Research Diets D12451); and in blue, mice fed a high-fat diet (60 
$1 \mathrm{kcal} \%$ from fat, HF60; Research Diets D12492). (A) RER: 'Fat clamp' (interaction: $F_{20,270}=25$,

$2 \quad P<0.0001$; time: $F_{10,270}=56.34, P<0.0001$; diets: $\left.F_{2,27}=29.13, P<0.0001\right)$; 'Sugar clamp'

3 (interaction: $F_{20,270}=0.64, P=0.87$; time: $F_{10,270}=65.72, P<0.0001$; diets: $F_{2,27}=2.87, P=$

4 0.07); 'Cal clamp' (interaction: $F_{20,270}=3.51, P<0.0001$; time: $F_{10,270}=49.89, P<0.0001$;

5 diets: $F_{2,27}=8.92, P=0.001$ ). (B) $\mathrm{VO}_{2}$ : 'Fat clamp' (interaction: $F_{20,270}=0.91, P=0.56$; time:

$6 \quad F_{10,270}=16.08, P<0.0001$; diets: $F_{2,27}=6.28, P<0.0001$ ); 'Sugar clamp' (interaction: $F_{20,270}=$

$7 \quad 0.18, P>0.99$; time: $F_{10,270}=14.66, P<0.0001$; diets: $\left.F_{2,27}=0.69, P=0.50\right)$; 'Cal clamp'

8 (interaction: $F_{20,270}=1.65, P=0.04$; time: $F_{10,270}=13.98, P<0.0001$; diets: $F_{2,27}=0.13, P=$

9 0.87). (C) $\mathrm{VCO}_{2}$ : 'Fat clamp' (interaction: $F_{20,270}=1.70, P=0.03$; time: $F_{10,270}=11.55, P<$

10 0.0001; diets: $F_{2,27}=22.47, P<0.0001$ ); 'Sugar clamp' (interaction: $F_{20,270}=0.28, P=0.99$;

11 time: $F_{10,270}=8.59, P<0.0001$; diets: $F_{2,27}=0.90, P=0.41$ ); 'Cal clamp' (interaction: $F_{20,270}=$

$121.30, P=0.17$; time: $F_{10,270}=10.33, P<0.0001$; diets: $\left.F_{2,27}=0.14, P=0.86\right)$. (D) Energy

13 expenditure: 'Fat clamp' (interaction: $F_{20,270}=0.84, P=0.66$; time: $F_{10,270}=14.62, P<0.0001$;

14 diets: $F_{2,27}=8.92, P=0.001$ ); 'Sugar clamp' (interaction: $F_{20,270}=0.19, P>0.99$; time: $F_{10,270}$

$15=12.9, P<0.0001$; diets: $F_{2,27}=0.67, P=0.51$ ); 'Cal clamp' (interaction: $F_{20,270}=1.55, P=$

160.06 ; time: $F_{10,270}=12.66, P<0.0001$; diets: $\left.F_{2,27}=0.08, P=0.91\right)$. (E) Ambulatory activity:

17 'Fat clamp' (interaction: $F_{20,270}=1.69, P=0.03$; time: $F_{10,270}=25.32, P<0.0001$; diets: $F_{2,27}=$

$180.23, P=0.78$ ); 'Sugar clamp' (interaction: $F_{20,270}=1.17, P=0.27$; time: $F_{10,270}=31.81, P<$

190.0001 ; diets: $F_{2,27}=1.01, P=0.37$ ); 'Cal clamp' (interaction: $F_{20,270}=1.68, P=0.03$; time: $F_{10}$,

$20270=26.55, P<0.0001$; diets: $\left.F_{2,27}=3.03, P=0.06\right) .(\mathbf{F})$ Fat utilization: 'Fat clamp'

21 (interaction: $F_{20,270}=19.24, P<0.0001$; time: $F_{10,270}=63.42, P<0.0001$; diets: $F_{2,27}=16.5, P$

$22<0.0001$ ); 'Sugar clamp' (interaction: $F_{20,270}=0.34, P=0.99$; time: $F_{10,270}=55.74, P<0.0001$;

23 diets: $F_{2,27}=2.65, P=0.08$ ); 'Cal clamp' (interaction: $F_{20,270}=3.22, P<0.0001$; time: $F_{10,270}=$ 
$1 \quad 55.86, P<0.0001$; diets: $\left.F_{2,27}=4.76, P=0.01\right)$. (G) Carbohydrate utilization: 'Fat clamp'

2 (interaction: $F_{20,270}=14.97, P<0.0001$; time: $F_{10,270}=30.32, P<0.0001$; diets: $F_{2,27}=45.82, P$

$3<0.0001$ ); 'Sugar clamp' (interaction: $F_{20,270}=0.67, P=0.84$; time: $F_{10,270}=44.44, P<0.0001$;

4 diets: $F_{2,27}=2.62, P=0.09$ ); 'Cal clamp' (interaction: $F_{20,270}=2.13, P=0.003$; time: $F_{10,270}=$

$544.43, P<0.0001$; diets: $\left.F_{2,27}=5.52, P=0.009\right)$. Statistical analysis was performed using two-

6 way ANOVA with time as a repeated measure followed by Holm-Sidak's multiple comparisons

7 test (MCT). MCTs are not shown. Dashed line indicates time of capsaicin injection. A total $\mathrm{n}=$

810 mice were used for each condition. Symbols indicate mean $\pm \mathrm{SEM}$. 
Figure 3
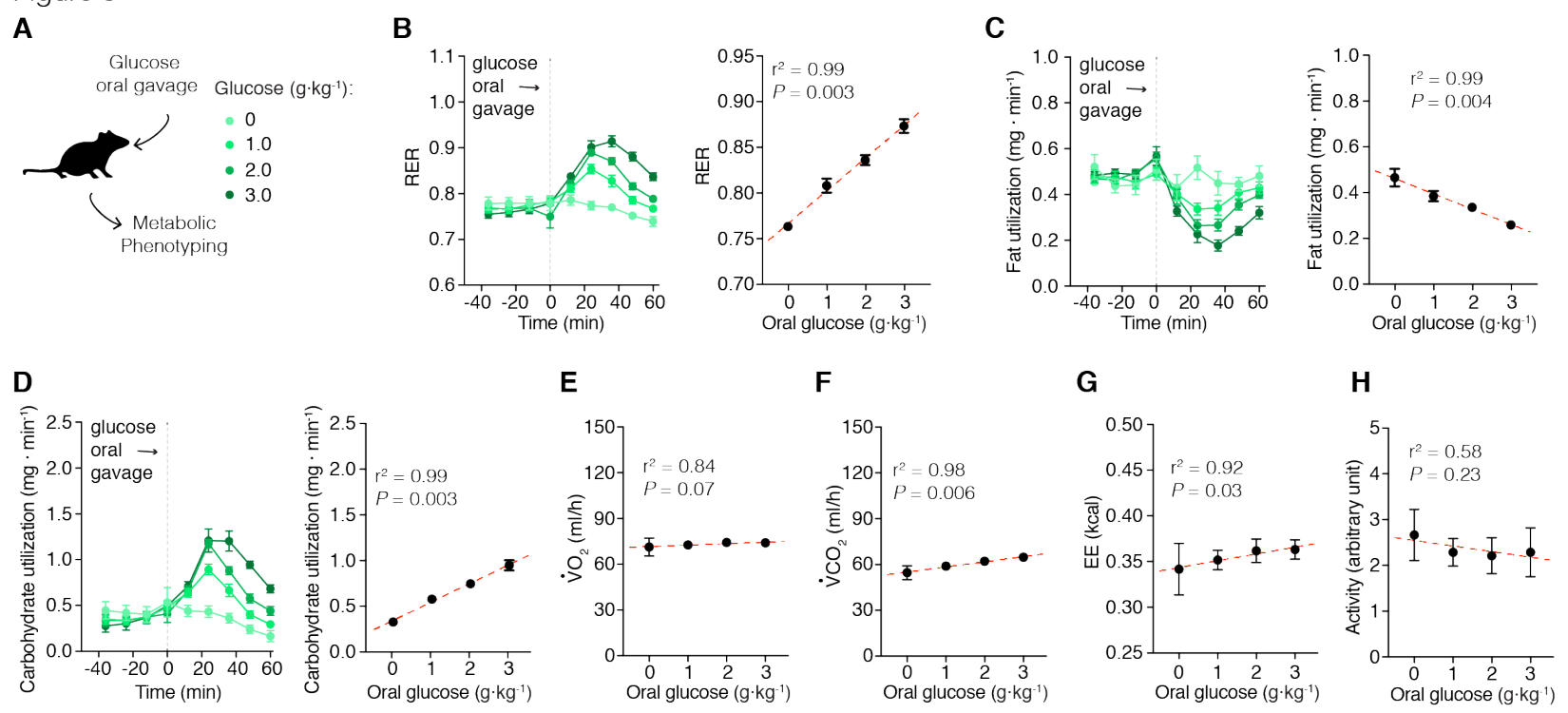

2 Figure 3: Acute effects of glucose on metabolism.

3 Metabolic phenotyping of mice immediately after a dose-response of glucose (via gavage). (A)

4 Mice received a bolus of saline or glucose solution $(1,2$, or $3 \mathrm{~g} / \mathrm{kg}$ body weight dissolved in

5 saline) via gavage. (B) Glucose gavage infusion produces an acute increase in RER that is dose

6 dependent. (C) Calculated fat utilization negatively correlates to glucose ingestion. (D)

7 Calculated carbohydrate utilization is positively correlated to glucose ingestion. (E) $\mathrm{VO}_{2}$ levels

8 did not correlated with glucose infusion. (F) $\mathrm{VCO}_{2}$ was positively correlated with glucose

9 ingestion. (G) Glucose gavage also positively correlated with energy expenditure measurements,

10 but did not correlated with changes in $(\mathbf{H})$ activity levels. The total number of animals used in

11 this study was: saline $(\mathrm{n}=7)$; glucose $1 \mathrm{~g} / \mathrm{kg}(\mathrm{n}=12)$; glucose $2 \mathrm{~g} / \mathrm{kg}(\mathrm{n}=16)$; and glucose 3

$12 \mathrm{~g} / \mathrm{kg}(\mathrm{n}=8)$. Symbols represent mean \pm SEM. Grey dashed line indicates time of oral gavage. In

13 the linear correlation panels, symbols indicate mean of all mice in the given group $\pm \mathrm{SEM}$;

14 dashed red line represents the linear regression model; $r^{2}$ and $P$ values are plotted in each panel. 
Figure 4

A

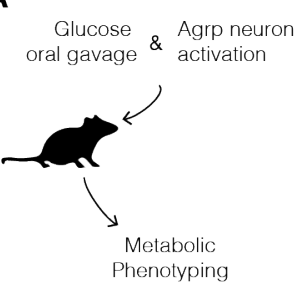

C

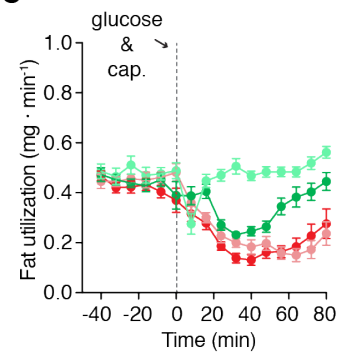

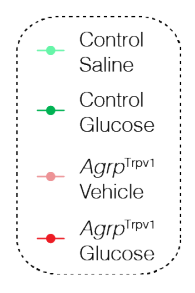

B

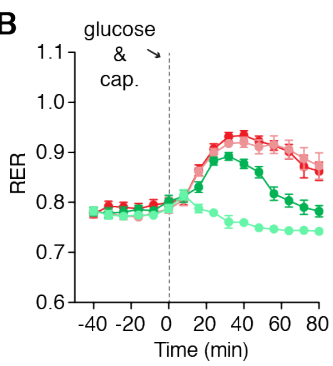

D
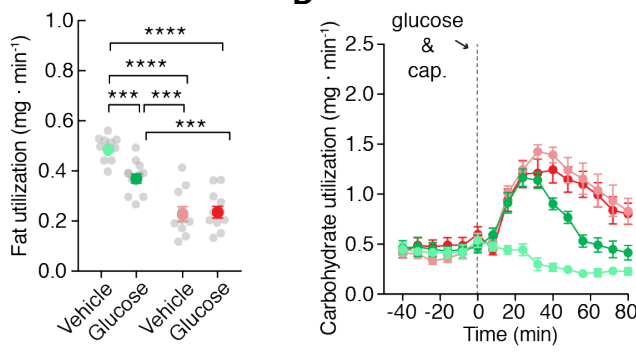

1

13 differences among groups. MCTs are indicated as $* P<0.05, * * P<0.01$, *** $P<0.001$, and

Figure 4: Agrp neurons control substrate utilization independently of ingestion.

(A) Control and $\operatorname{Agrp}^{\text {Trpv1 }}$ mice received a bolus of saline or glucose $(2 \mathrm{~g} / \mathrm{kg})$ via gavage

followed by peripheral injection of capsaicin $(10 \mathrm{mg} / \mathrm{kg}$, i.p.). (B) Changes in RER in control mice fed different doses of glucose solutions (interaction: $F_{1,40}=9.82, P=0.003$; gavage solution: $F_{1,40}=8.20, P=0.006$; genotype: $\left.F_{1,40}=71.31, P<0.0001\right)$. (C) Fat utilization (interaction: $F_{1,40}=7.91, P=0.007$; gavage solution: $F_{1,40}=6.07, P=0.01$; genotype: $F_{1,40}=$ 79.82, $P<0.0001$ ). (D) Carbohydrate utilization: (interaction: $F_{1,40}=8.29, P=0.006$; gavage solution: $F_{1,40}=5.26, P=0.02$; genotype: $\left.F_{1,40}=37.44, P<0.0001\right)$. Statistical analysis was performed using two-way ANOVA on the mean response after gavage and capsaicin injection; genotype (control vs. Agrp $^{\text {Trpv1 }}$ ) and gavage infusion (saline vs. glucose) were used as factors for the ANOVA. Holm-Sidak's multiple comparisons test (MCT) was used to find post-hoc
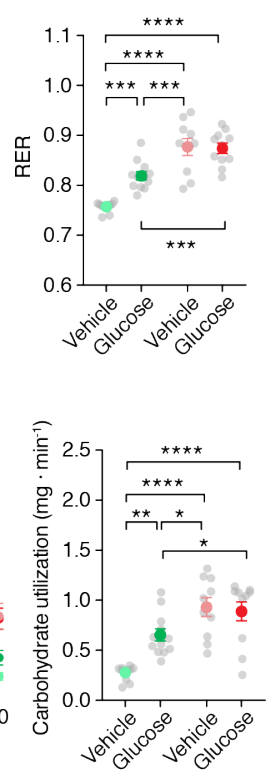
**** $P<0.0001$ in figure panels. Control mice + saline gavage $(\mathrm{n}=11)$; control mice + glucose 15 gavage $(\mathrm{n}=12) ; \operatorname{Agrp}^{\text {Trpv1 }}$ mice + saline gavage $(\mathrm{n}=10) ; \operatorname{Agrp}^{\text {Trpv1 }}$ mice + glucose gavage $(\mathrm{n}=$ 
bioRxiv preprint doi: https://doi.org/10.1101/086348; this version posted November 7, 2016. The copyright holder for this preprint (which was not certified by peer review) is the author/funder, who has granted bioRxiv a license to display the preprint in perpetuity. It is made available under aCC-BY-NC-ND 4.0 International license.

1 11). Dashed grey line indicates time of oral gavage and capsaicin injection. Colored symbols

2 indicate mean \pm SEM. Grey symbols indicate individual values. 
Figure 4 supplement 1
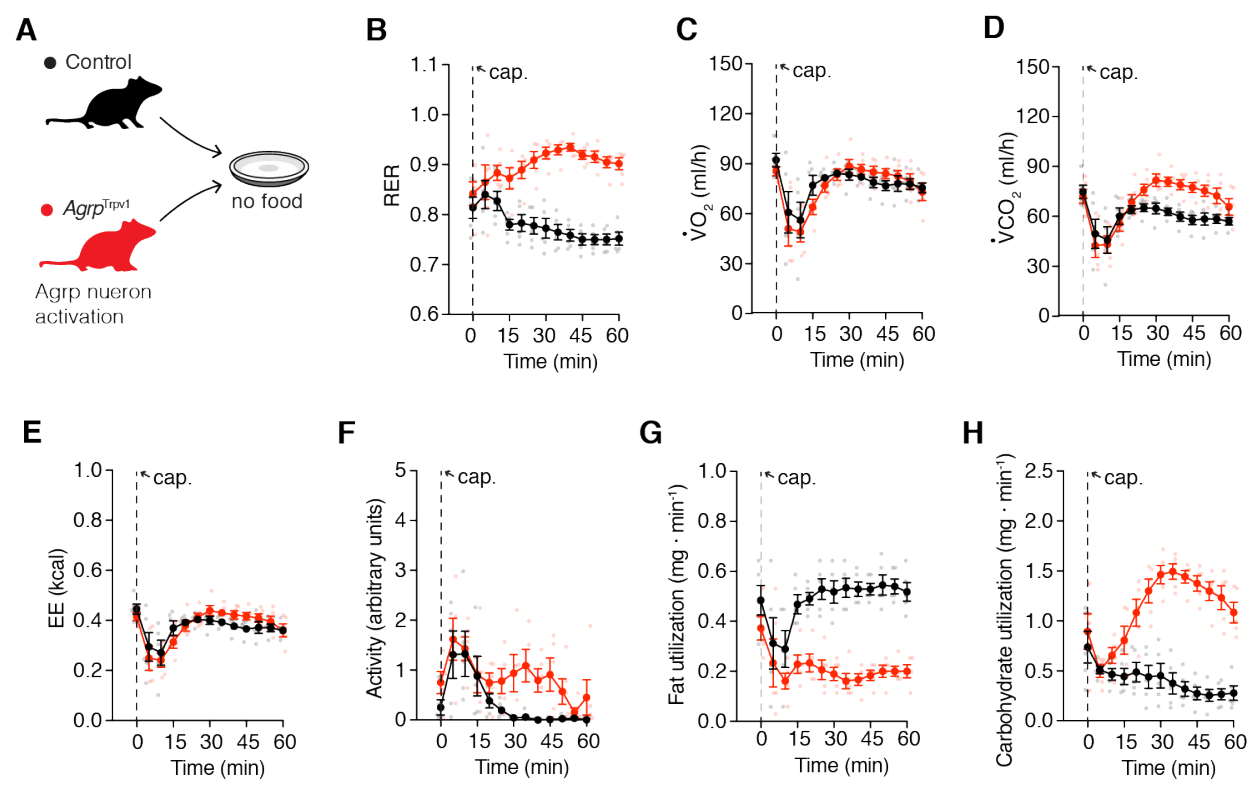

\section{Figure 4 supplement 1: Agrp neurons control substrate utilization independently of}

\section{3 ingestion.}

4 (A) Well-fed control (in black) and $\operatorname{Agrp}^{\text {Trpv1 }}$ (in red) mice were tested in metabolic chambers

5 upon injection of capsaicin without food provided. (B) RER (interaction: $F_{12,96}=8.96, P<$ 0.0001; time: $F_{12,96}=1.31, P=0.22$; genotype: $\left.F_{1,8}=54.45, P<0.0001\right)$. (C) $\mathrm{VO}_{2}$ (interaction:

$7 \quad F_{12,96}=0.87, P=0.57$; time: $F_{12,96}=9.63, P<0.0001$; genotype: $\left.F_{1,8}=0.15, P=0.70\right)$.

8 (D) $\mathrm{VCO}_{2}$ (interaction: $F_{12,96}=2.89, P=0.001$; time: $F_{12,96}=10.66, P<0.0001$; genotype: $F_{1,8}$

$9=10.39, P=0.01)$. (E) Energy expenditure (interaction: $F_{12,96}=1.16, P=0.31$; time: $F_{12,96}=$

$109.89, P<0.0001$; genotype: $F_{1,8}=0.13, P=0.72$ ). (F) Ambulatory activity (interaction: $F_{12,96}=$

11 1.12, $P=0.34$; time: $F_{12,96}=7.13, P<0.0001$; genotype: $\left.F_{1,8}=5.29, P=0.05\right)$. (G) Calculated

12 fat utilization (interaction: $F_{12,96}=3.52, P=0.0002$; time: $F_{12,96}=3.23, P=0.0006$; genotype:

$\left.13 F_{1,8}=55.31, P<0.0001\right)$. (H) Calculated carbohydrate utilization (interaction: $F_{12,96}=13.52, P$

$14<0.0001$; time: $F_{12,96}=6.25, P<0.0001$; genotype: $\left.F_{1,8}=58.16, P<0.0001\right)$. Statistical

15 analysis was performed using two-way ANOVA with time as a repeated measure followed by 
1 Holm-Sidak's multiple comparisons test (MCT). MCTs are not shown. Dashed line indicates

2 time of capsaicin injection. Small symbols indicate individual values. Large symbols indicate

3 mean \pm SEM. 
Figure 5

A

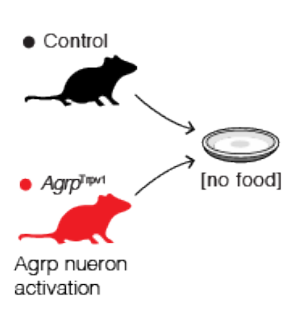

E
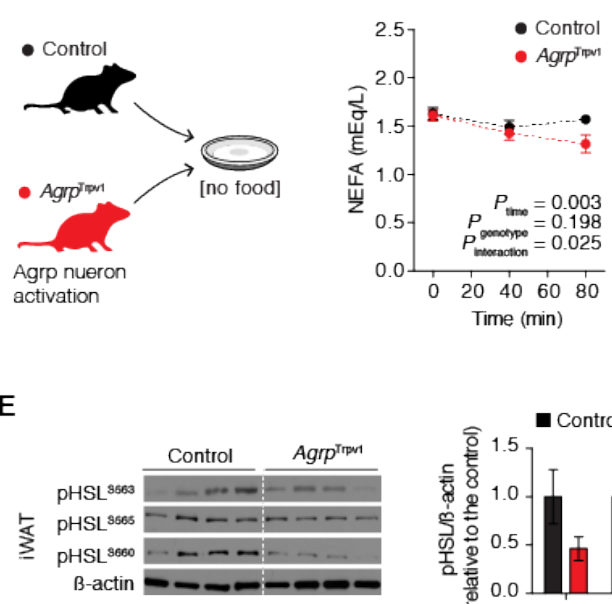

C

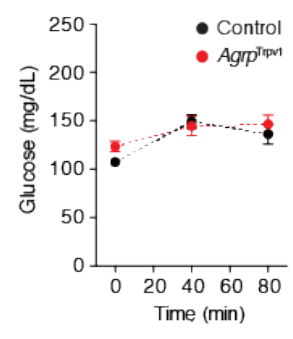

D

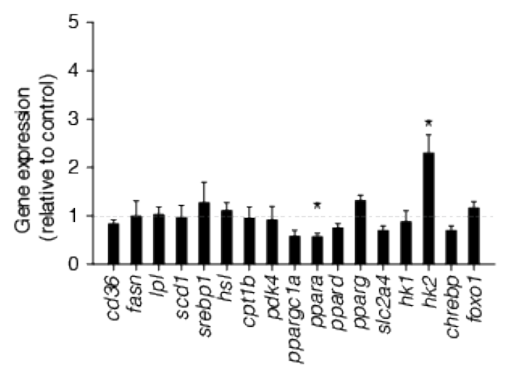

F

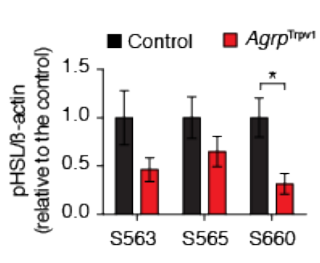

F

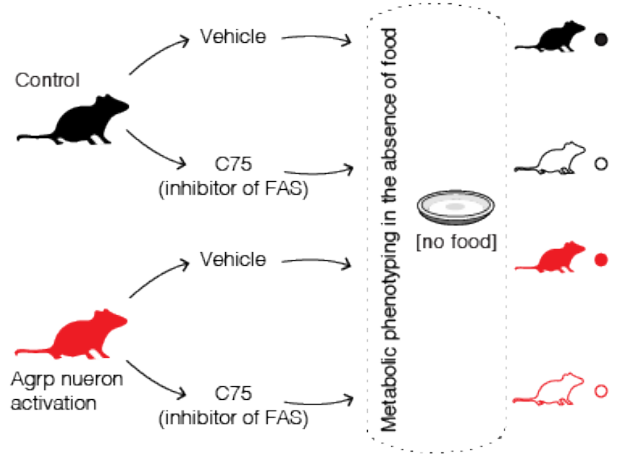

G

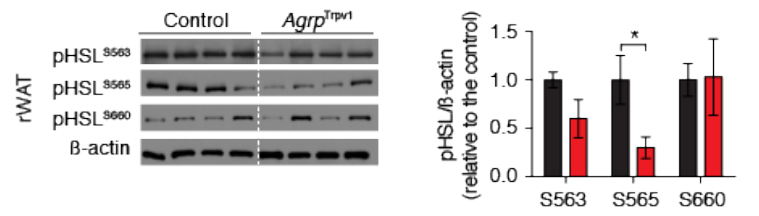

H
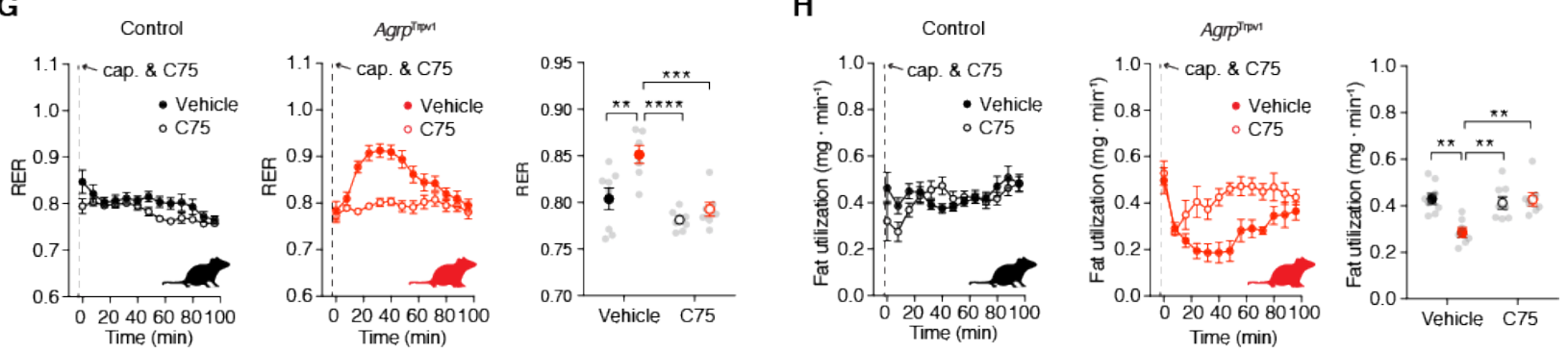

I
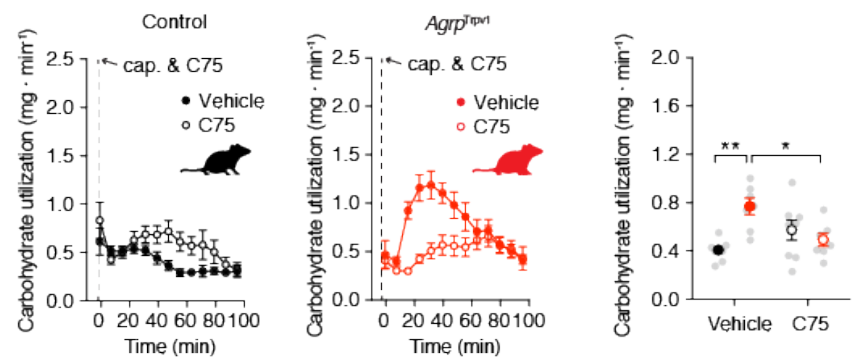

\section{Figure 5: Agrp neurons promote lipogenesis.}

3 (A) Well-fed control (in black) and $A g r p^{\text {Trpv1 }}$ (in red) mice were injected with capsaicin (10

$4 \mathrm{mg} / \mathrm{kg}$, i.p.). One group of animals was tail bled before and after (40 and $80 \mathrm{~min}$ ) injection to

measure blood levels of NEFA and glucose. Different groups of animals were sacrificed 60 
1 minutes after capsaicin injection and white adipose tissue (WAT) was collected for biochemical

2 analyses. (B) NEFA levels (interaction: $F_{2,54}=3.91, P=0.02$; time: $F_{2,54}=9.64, P=0.0003$;

3 genotype: $F_{1,27}=1.74, P=0.19$; MCT: $P_{80 \text { min }}=0.03$ ). (C) Blood glucose levels (interaction: $F_{2}$,

$4 \quad 54=1.47, P=0.23$; time: $F_{2,54}=14.6, P<0.0001$; genotype: $F_{1,27}=0.67, P=0.41 ;$ MCT: not

5 significant). In B and C: control $(\mathrm{n}=15)$ and $\operatorname{Agrp}^{\text {Trpv1 }}$ mice $(\mathrm{n}=14)$. Statistical analysis was

6 performed using two-way ANOVA with time as a repeated measure followed by Holm-Sidak's

7 multiple comparisons test (MCT). (D) Analysis of the transcriptional profile of the WAT upon

8 activation of Agrp neurons. Data are normalized to control levels (dashed line). Statistical

9 analysis was performed using student's $t$-test. $* P<0.05$. (E) Western blotting analysis of

10 phosphorylated HSL in inguinal WAT and retroperitoneal WAT ( $\mathrm{n}=4$ mice per group).

11 Statistical analysis was performed using student's $t$-test. $* P<0.05$. (F) Experimental design to

12 test the participation of fatty acid synthetase (FAS) in the effects of Agrp neurons on substrate

13 utilization. Control and $\operatorname{Agrp}^{\text {Trpv1 }}$ mice were randomized to receive vehicle or the FAS inhibitor

$14\left(\mathrm{C} 75,10 \mathrm{mg} / \mathrm{kg}\right.$, i.p.) immediately before capsaicin injection. (G) RER (interaction: $F_{1,26}=4.36$,

$15 P=0.04$; drug: $F_{1,26}=22.28, P<0.0001$; genotype: $\left.F_{1,26}=11.73, P=0.002\right) .(\mathbf{H})$ Fat

16 utilization (interaction: $F_{1,26}=9.97, P=0.04$; drug: $F_{1,26}=6.00, P=0.02$; genotype: $F_{1,26}=$

17 6.56, $P=0.01$ ). (I) Carbohydrate utilization: (interaction: $F_{1,26}=12.18, P=0.001$; drug: $F_{1,26}=$

$180.76, P=0.38$; genotype: $\left.F_{1,26}=4.90, P=0.03\right)$. In G-I, statistical analysis was performed using

19 two-way ANOVA on the mean response after drug and capsaicin injection; genotype (control vs.

$20 \mathrm{Agrp}^{\text {Trpv1}}$ ) and drug (vehicle vs. C75) were used as factors for the ANOVA. Holm-Sidak's

21 multiple comparisons test (MCT) was used to find post-hoc differences among groups. MCTs are

22 indicated as $* P<0.05, * * P<0.01, * * * P<0.001$, and $* * * * P<0.0001$ in figure panels.

23 Control mice + vehicle $(\mathrm{n}=8)$; control mice + C75 $(\mathrm{n}=8) ; \operatorname{Agrp}^{\text {Trpv1 }}$ mice + vehicle $(\mathrm{n}=7)$; 
bioRxiv preprint doi: https://doi.org/10.1101/086348; this version posted November 7, 2016. The copyright holder for this preprint (which was not certified by peer review) is the author/funder, who has granted bioRxiv a license to display the preprint in perpetuity. It is made available under aCC-BY-NC-ND 4.0 International license.

$1 \operatorname{Agrp}^{\text {Trpv1 }}$ mice $+\mathrm{C} 75(\mathrm{n}=7)$. Dashed line indicates time of injections. Colored symbols indicate

2 mean \pm SEM. Grey symbols indicate individual values. 
Figure 6

A
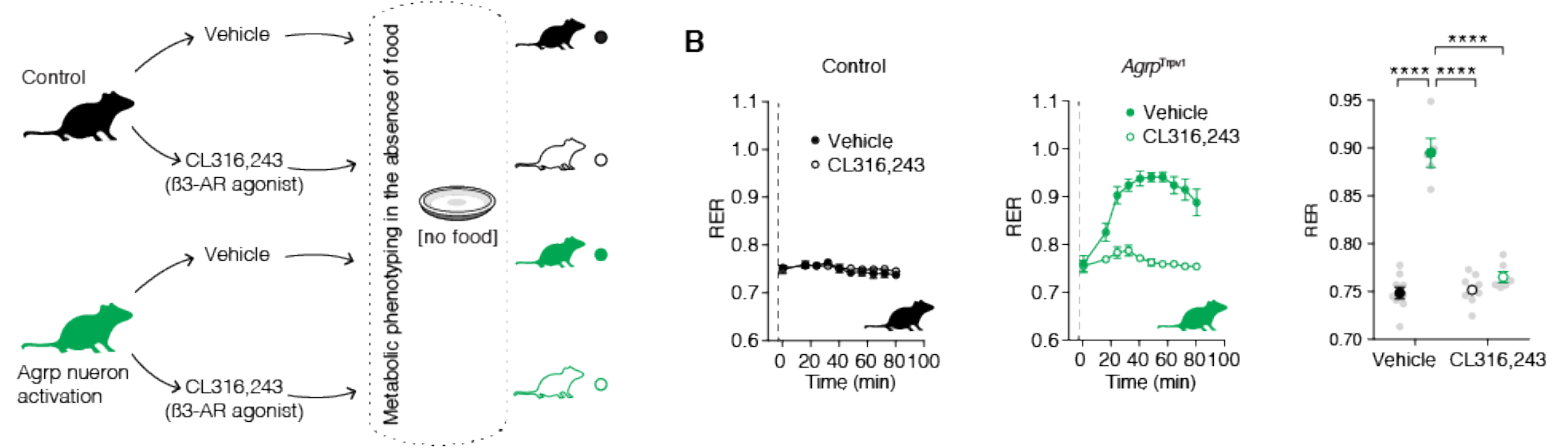

C
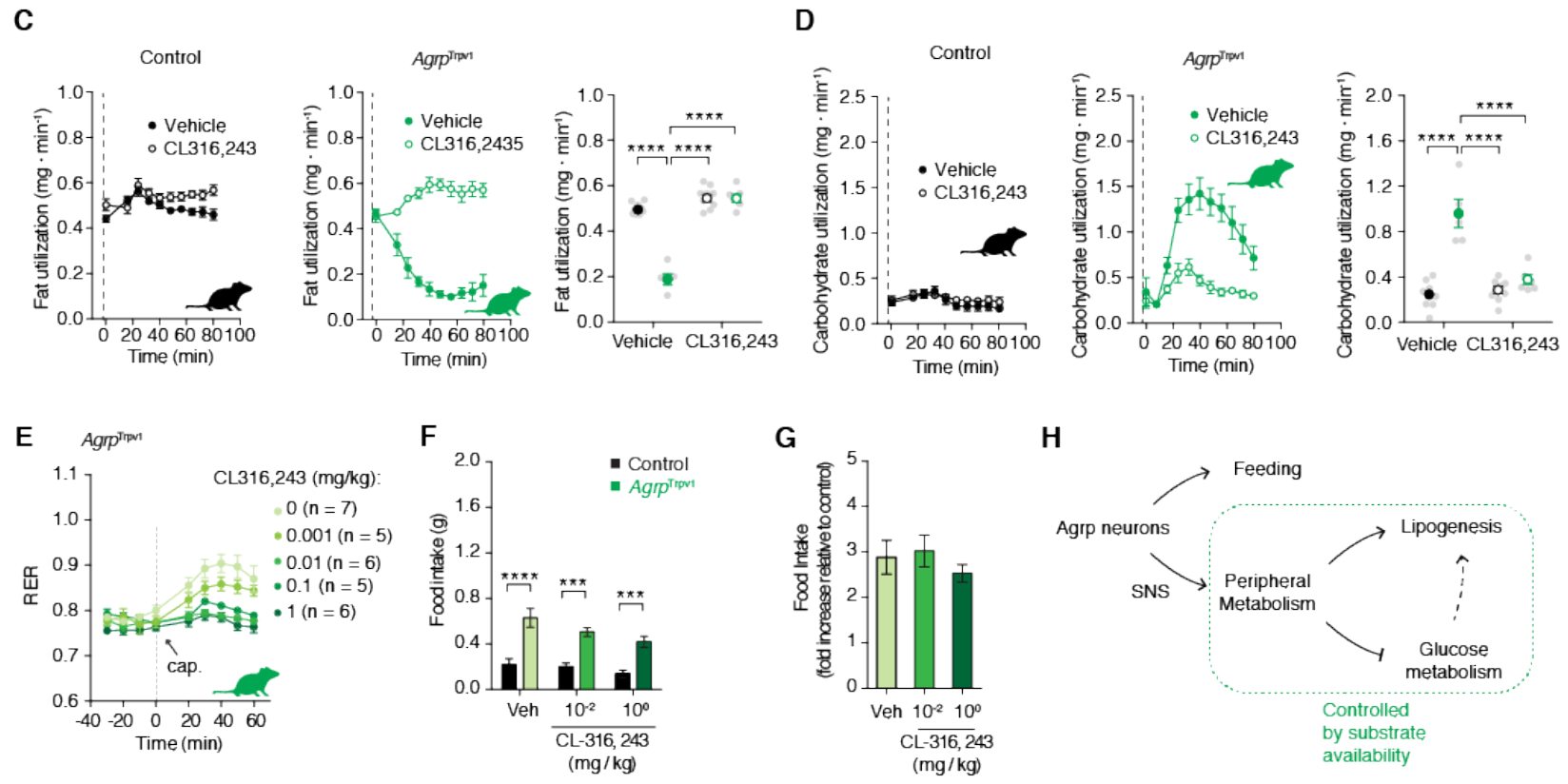

Figure 6: SNS signaling is involved in peripheral effects of Agrp neurons.

3 (A) Experimental design to test the participation of the sympathetic nervous system (SNS) in the

4 effects of Agrp neurons on substrate utilization. Control (black) and $\operatorname{Agrp}^{\text {Trpv1 }}$ mice (green) were

5 randomized to receive vehicle or the 33 -adrenergic receptor agonist (CL316,243, $1 \mathrm{mg} / \mathrm{kg}$, i.p.);

6 vehicle or CL316,243 were injected immediately before capsaicin. (B) RER (interaction: $F_{1,25}=$

7 75.09, $P<0.0001$; drug: $F_{1,25}=67.96, P<0.0001$; genotype: $\left.F_{1,25}=108.4, P<0.0001\right)$. (C) Fat

8 utilization (interaction: $F_{1,25}=85.56, P<0.0001$; drug: $F_{1,25}=150.4, P<0.0001$; genotype: $F_{1}$,

$925=86.42, P<0.0001$ ). (D) Carbohydrate utilization: (interaction: $F_{1,25}=29.74, P<0.0001$;

10 drug: $F_{1,25}=22.75, P<0.0001$; genotype: $\left.F_{1,25}=50.12, P<0.0001\right)$. In B-D, statistical analysis 
1 was performed using two-way ANOVA on the mean response after drug and capsaicin injection;

2 genotype (control vs. Agrp $^{\text {Trpv1 }}$ ) and drug (vehicle vs. CL316,243) were used as factors for the

3 ANOVA. Holm-Sidak's multiple comparisons test (MCT) was used to find post-hoc differences

4 among groups. MCTs are indicated as $* P<0.05$, ** $P<0.01$, *** $P<0.001$, and **** $P<$

50.0001 in figure panels. Control mice + vehicle $(n=9)$; control mice + CL316,243 $(n=9)$;

$6 \quad \operatorname{Agrp}^{\text {Trpv1}}$ mice + vehicle $(\mathrm{n}=5) ; \operatorname{Agrp}^{\text {Trpv1 }}$ mice + CL316,243 $(\mathrm{n}=6)$. Dashed line indicates time

7 of injections. Colored symbols indicate mean \pm SEM. Grey symbols indicate individual values.

8 (E) Dose-response of CL316,243 injected immediately before capsaicin in Agrp $^{\text {Trpv1 }}$ mice

9 (dashed line denotes injection time). Number of animals used per experimental group shown in

10 the panel. (F) Food intake response of control and Agrp $^{\text {Trpv1 }}$ mice to activation of Agrp neurons

11 when injected with different doses of CL316,243 $\left(\mathrm{n}=7\right.$ for all groups); interaction $\left(F_{2,36}=0.95\right.$,

$12 P=0.39) ; \operatorname{drug}\left(F_{2,36}=4.16, P=0.02\right)$; genotype $\left(F_{1,36}=64.96, P<0.0001\right)$. Statistical analysis

13 was performed using two-way ANOVA with genotype and drug as factors. Holm-Sidak's

14 multiple comparisons test (MCT) was used to find post-hoc differences genotypes. MCTs are

15 indicated as $* * * P<0.001$ and $* * * * P<0.0001$ in figure panel. (G) Related to $\mathrm{F}$, but fold

16 change in food intake in Agrp $^{\text {Trpv1 }}$ related to control mice. Bars and symbols indicate mean \pm

17 SEM. (H) Diagram illustrating the model for different roles of Agrp neurons in the control of

18 feeding and peripheral metabolism. Agrp neurons control peripheral metabolism via the SNS, but

19 switching substrate utilization towards use of carbohydrate. 


\section{References}

Aponte, Y., Atasoy, D., and Sternson, S.M. (2011). AGRP neurons are sufficient to orchestrate feeding behavior rapidly and without training. Nature neuroscience 14, 351-355.

Arenkiel, B.R., Klein, M.E., Davison, I.G., Katz, L.C., and Ehlers, M.D. (2008). Genetic control of neuronal activity in mice conditionally expressing TRPV1. Nature methods 5, 299-302.

Bartness, T.J., Liu, Y., Shrestha, Y.B., and Ryu, V. (2014). Neural innervation of white adipose tissue and the control of lipolysis. Frontiers in neuroendocrinology 35, 473-493.

8 Baver, S.B., Hope, K., Guyot, S., Bjorbaek, C., Kaczorowski, C., and O'Connell, K.M. (2014). Leptin modulates the intrinsic excitability of AgRP/NPY neurons in the arcuate nucleus of the

10 hypothalamus. The Journal of neuroscience : the official journal of the Society for Neuroscience $1134,5486-5496$.

12 Betley, J.N., Cao, Z.F., Ritola, K.D., and Sternson, S.M. (2013). Parallel, redundant circuit 13 organization for homeostatic control of feeding behavior. Cell 155, 1337-1350.

14 Betley, J.N., Xu, S., Cao, Z.F., Gong, R., Magnus, C.J., Yu, Y., and Sternson, S.M. (2015).

15 Neurons for hunger and thirst transmit a negative-valence teaching signal. Nature 521, 180-185.

16 Bloom, J.D., Dutia, M.D., Johnson, B.D., Wissner, A., Burns, M.G., Largis, E.E., Dolan, J.A., 17 and Claus, T.H. (1992). Disodium (R,R)-5-[2-[[2-(3-chlorophenyl)-2-hydroxyethyl]-amino] 18 propyl]-1,3-benzodioxole-2,2-dicarboxylate (CL 316,243). A potent beta-adrenergic agonist 19 virtually specific for beta 3 receptors. A promising antidiabetic and antiobesity agent. J Med

20 Chem 35, 3081-3084.

21 Broadwell, R.D., Balin, B.J., Salcman, M., and Kaplan, R.S. (1983). Brain-blood barrier? Yes 22 and no. Proceedings of the National Academy of Sciences of the United States of America 80, 23 7352-7356.

24 Broadwell, R.D., and Brightman, M.W. (1976). Entry of peroxidase into neurons of the central 25 and peripheral nervous systems from extracerebral and cerebral blood. The Journal of 26 comparative neurology 166, 257-283.

27 Broberger, C., Johansen, J., Johansson, C., Schalling, M., and Hökfelt, T. (1998). The

28 neuropeptide Y/agouti gene-related protein (AGRP) brain circuitry in normal, anorectic, and 29 monosodium glutamate-treated mice. Proceedings of the National Academy of Sciences of the 30 United States of America 95, 15043-15048. 
1 Caterina, M.J., Schumacher, M.A., Tominaga, M., Rosen, T.A., Levine, J.D., and Julius, D.

2 (1997). The capsaicin receptor: a heat-activated ion channel in the pain pathway. Nature 389,

3 816-824.

4 Chen, Y., Lin, Y.C., Kuo, T.W., and Knight, Z.A. (2015). Sensory detection of food rapidly

5 modulates arcuate feeding circuits. Cell 160, 829-841.

6 Clark, J.T., Kalra, P.S., Crowley, W.R., and Kalra, S.P. (1984). Neuropeptide Y and human

7 pancreatic polypeptide stimulate feeding behavior in rats. Endocrinology 115, 427-429.

8 Correll, J.W. (1963). Adipose tissue: ability to respond to nerve stimulation in vitro. Science 140, $9 \quad 387-388$.

10 Diano, S., Liu, Z.W., Jeong, J.K., Dietrich, M.O., Ruan, H.B., Kim, E., Suyama, S., Kelly, K.,

11 Gyengesi, E., Arbiser, J.L., et al. (2011). Peroxisome proliferation-associated control of reactive

12 oxygen species sets melanocortin tone and feeding in diet-induced obesity. Nature medicine 17 ,

13 1121-U1130.

14 Dietrich, M.O., Bober, J., Ferreira, J.G., Tellez, L.A., Mineur, Y.S., Souza, D.O., Gao, X.B., 15 Picciotto, M.R., Araujo, I., Liu, Z.W., et al. (2012). AgRP neurons regulate development of 16 dopamine neuronal plasticity and nonfood-associated behaviors. Nature neuroscience 15,1108 171010.

18 Dietrich, M.O., Liu, Z.W., and Horvath, T.L. (2013). Mitochondrial dynamics controlled by 19 mitofusins regulate agrp neuronal activity and diet-induced obesity. Cell 155, 188-199.

20 Dietrich, M.O., Zimmer, M.R., Bober, J., and Horvath, T.L. (2015). Hypothalamic Agrp Neurons 21 Drive Stereotypic Behaviors beyond Feeding. Cell 160, 1222-1232.

22 Frayn, K.N. (1983). Calculation of substrate oxidation rates in vivo from gaseous exchange.

23 Journal of applied physiology: respiratory, environmental and exercise physiology 55, 628-634.

24 Gropp, E., Shanabrough, M., Borok, E., Xu, A.W., Janoschek, R., Buch, T., Plum, L., Balthasar,

25 N., Hampel, B., Waisman, A., et al. (2005). Agouti-related peptide-expressing neurons are

26 mandatory for feeding. Nature neuroscience 8, 1289-1291.

27 Grove, K.L., Chen, P., Koegler, F.H., Schiffmaker, A., Susan Smith, M., and Cameron, J.L.

28 (2003). Fasting activates neuropeptide Y neurons in the arcuate nucleus and the paraventricular

29 nucleus in the rhesus macaque. Brain Res Mol Brain Res 113, 133-138.

30 Grujic, D., Susulic, V.S., Harper, M.E., Himms-Hagen, J., Cunningham, B.A., Corkey, B.E., and

31 Lowell, B.B. (1997). Beta3-adrenergic receptors on white and brown adipocytes mediate beta3-

32 selective agonist-induced effects on energy expenditure, insulin secretion, and food intake. A 
study using transgenic and gene knockout mice. The Journal of biological chemistry 272, 17686-

217693.

3 Guler, A.D., Rainwater, A., Parker, J.G., Jones, G.L., Argilli, E., Arenkiel, B.R., Ehlers, M.D., 4 Bonci, A., Zweifel, L.S., and Palmiter, R.D. (2012). Transient activation of specific neurons in 5 mice by selective expression of the capsaicin receptor. Nature communications 3, 746.

Hahn, T.M., Breininger, J.F., Baskin, D.G., and Schwartz, M.W. (1998). Coexpression of Agrp and NPY in fasting-activated hypothalamic neurons. Nature neuroscience 1, 271-272.

8 Joly-Amado, A., Denis, R.G., Castel, J., Lacombe, A., Cansell, C., Rouch, C., Kassis, N., 9 Dairou, J., Cani, P.D., Ventura-Clapier, R., et al. (2012). Hypothalamic AgRP-neurons control 10 peripheral substrate utilization and nutrient partitioning. The EMBO journal 31, 4276-4288.

11 Könner, A., Janoschek, R., Plum, L., Jordan, S., Rother, E., Ma, X., Xu, C., Enriori, P., Hampel, 12 B., Barsh, G., et al. (2007). Insulin action in AgRP-expressing neurons is required for

13 suppression of hepatic glucose production. Cell metabolism 5, 438-449.

14 Krashes, M.J., Koda, S., Ye, C., Rogan, S.C., Adams, A.C., Cusher, D.S., Maratos-Flier, E., 15 Roth, B.L., and Lowell, B.B. (2011). Rapid, reversible activation of AgRP neurons drives

16 feeding behavior in mice. The Journal of clinical investigation 121, 1424-1428.

17 Kuhajda, F.P., Pizer, E.S., Li, J.N., Mani, N.S., Frehywot, G.L., and Townsend, C.A. (2000).

18 Synthesis and antitumor activity of an inhibitor of fatty acid synthase. Proceedings of the

19 National Academy of Sciences of the United States of America 97, 3450-3454.

20 Lodhi, I.J., Yin, L., Jensen-Urstad, A.P., Funai, K., Coleman, T., Baird, J.H., El Ramahi, M.K., 21 Razani, B., Song, H., Fu-Hsu, F., et al. (2012). Inhibiting adipose tissue lipogenesis reprograms 22 thermogenesis and PPARgamma activation to decrease diet-induced obesity. Cell metabolism

$2316,189-201$.

24 Loftus, T.M., Jaworsky, D.E., Frehywot, G.L., Townsend, C.A., Ronnett, G.V., Lane, M.D., and 25 Kuhajda, F.P. (2000). Reduced food intake and body weight in mice treated with fatty acid 26 synthase inhibitors. Science 288, 2379-2381.

27 Luquet, S., Perez, F., Hnasko, T., and Palmiter, R. (2005). NPY/AgRP neurons are essential for 28 feeding in adult mice but can be ablated in neonates. Science 310, 683-685.

29 Mandelblat-Cerf, Y., Ramesh, R.N., Burgess, C.R., Patella, P., Yang, Z., Lowell, B.B., and 30 Andermann, M.L. (2015). Arcuate hypothalamic AgRP and putative POMC neurons show 31 opposite changes in spiking across multiple timescales. Elife 4. 
1 Ollmann, M.M., Wilson, B.D., Yang, Y.K., Kerns, J.A., Chen, Y., Gantz, I., and Barsh, G.S.

2 (1997). Antagonism of central melanocortin receptors in vitro and in vivo by agouti-related

3 protein. Science 278, 135-138.

4 Olofsson, L.E., Unger, E.K., Cheung, C.C., and Xu, A.W. (2013). Modulation of AgRP-neuronal

5 function by SOCS3 as an initiating event in diet-induced hypothalamic leptin resistance.

6 Proceedings of the National Academy of Sciences of the United States of America 110, E697-

7706.

8 Padilla, S.L., Qiu, J., Soden, M.E., Sanz, E., Nestor, C.C., Barker, F.D., Quintana, A., Zweifel, 9 L.S., Ronnekleiv, O.K., Kelly, M.J., et al. (2016). Agouti-related peptide neural circuits mediate

10 adaptive behaviors in the starved state. Nature neuroscience 19, 734-741.

11 Pinto, S., Roseberry, A.G., Liu, H., Diano, S., Shanabrough, M., Cai, X., Friedman, J.M., and

12 Horvath, T.L. (2004). Rapid rewiring of arcuate nucleus feeding circuits by leptin. Science 304,

13 110-115.

14 Rossi, M., Kim, M.S., Morgan, D.G., Small, C.J., Edwards, C.M., Sunter, D., Abusnana, S., 15 Goldstone, A.P., Russell, S.H., Stanley, S.A., et al. (1998). A C-terminal fragment of Agouti16 related protein increases feeding and antagonizes the effect of alpha-melanocyte stimulating 17 hormone in vivo. Endocrinology 139, 4428-4431.

18 Ruan, H.B., Dietrich, M.O., Liu, Z.W., Zimmer, M.R., Li, M.D., Singh, J.P., Zhang, K., Yin, R., 19 Wu, J., Horvath, T.L., et al. (2014). O-GlcNAc Transferase Enables AgRP Neurons to Suppress 20 Browning of White Fat. Cell 159, 306-317.

21 Rutkowski, J.M., Stern, J.H., and Scherer, P.E. (2015). The cell biology of fat expansion. The 22 Journal of cell biology 208, 501-512.

23 Srisai, D.H., Yong; Meng, Fantao; He, Yanlin; Chen, Wenwen; Kodirov, Sodikdjon; Dong, 24 Sicong; Farias, Monica; Tóth, István; Lee, Amy; Dietrich, Marcelo O.; Xu, Yong; Wu, Qi

25 (2016). Deciphering an AgRP-Dorsal Raphe neural circuit in exclusive control of energy

26 expenditure. Cell (Submitted).

27 Steculorum, S.M., Paeger, L., Bremser, S., Evers, N., Hinze, Y., Idzko, M., Kloppenburg, P., and 28 Bruning, J.C. (2015). Hypothalamic UDP Increases in Obesity and Promotes Feeding via P2Y629 Dependent Activation of AgRP Neurons. Cell 162, 1404-1417.

30 Steculorum, S.M., Ruud, J., Karakasilioti, I., Backes, H., Engstrom Ruud, L., Timper, K., Hess, 31 M.E., Tsaousidou, E., Mauer, J., Vogt, M.C., et al. (2016). AgRP Neurons Control Systemic 32 Insulin Sensitivity via Myostatin Expression in Brown Adipose Tissue. Cell 165, 125-138. 
1 Takahashi, K.A., and Cone, R.D. (2005). Fasting induces a large, leptin-dependent increase in

2 the intrinsic action potential frequency of orexigenic arcuate nucleus neuropeptide Y/Agouti-

3 related protein neurons. Endocrinology 146, 1043-1047.

4 van den Top, M., Lee, K., Whyment, A.D., Blanks, A.M., and Spanswick, D. (2004). Orexigen-

5 sensitive NPY/AgRP pacemaker neurons in the hypothalamic arcuate nucleus. Nature

6 neuroscience 7, 493-494.

7 Wei, W., Pham, K., Gammons, J.W., Sutherland, D., Liu, Y., Smith, A., Kaczorowski, C.C., and 8 O'Connell, K.M. (2015). Diet composition, not calorie intake, rapidly alters intrinsic excitability 9 of hypothalamic AgRP/NPY neurons in mice. Scientific reports 5, 16810.

$10 \mathrm{Wu}$, Q., and Palmiter, R.D. (2011). GABAergic signaling by AgRP neurons prevents anorexia 11 via a melanocortin-independent mechanism. European journal of pharmacology 660, 21-27.

12 Zeng, W., Pirzgalska, R.M., Pereira, M.M., Kubasova, N., Barateiro, A., Seixas, E., Lu, Y.H., 13 Kozlova, A., Voss, H., Martins, G.G., et al. (2015). Sympathetic neuro-adipose connections 14 mediate leptin-driven lipolysis. Cell 163, 84-94. 